\title{
Microglial Cells Prevent Hemorrhage in Neonatal Focal Arterial Stroke
}

\author{
David Fernández-López, ${ }^{1}$ Joel Faustino, ${ }^{1}$ Alexander L. Klibanov, ${ }^{2}$ Nikita Derugin, ${ }^{1}$ Elodie Blanchard, ${ }^{1}$ \\ Franziska Simon, ${ }^{3}$ CStephen L. Leib, ${ }^{3}$ and Zinaida S. Vexler ${ }^{1}$ \\ ${ }^{1}$ Department of Neurology, University of California-San Francisco, San Francisco, California 94158, ${ }^{2}$ Department of Medicine, University of Virginia, \\ Charlottesville, Virginia 22908, and ${ }^{3}$ Institute for Infectious Diseases, University of Bern, 3001 Bern, Switzerland
}

Perinatal stroke leads to significant morbidity and long-term neurological and cognitive deficits. The pathophysiological mechanisms of brain damage depend on brain maturation at the time of stroke. To understand whether microglial cells limit injury after neonatal stroke by preserving neurovascular integrity, we subjected postnatal day 7 (P7) rats depleted of microglial cells, rats with inhibited microglial TGFbr2/ALK5 signaling, and corresponding controls, to transient middle cerebral artery occlusion (tMCA0). Microglial depletion by intracerebral injection of liposome-encapsulated clodronate at P5 significantly reduced vessel coverage and triggered hemorrhages in injured regions $24 \mathrm{~h}$ after tMCAO. Lack of microglia did not alter expression or intracellular redistribution of several tight junction proteins, did not affect degradation of collagen IV induced by the tMCAO, but altered cell types producing TGF $\beta 1$ and the phosphorylation and intracellular distribution of SMAD2/3. Selective inhibition of TGFbr2/ALK5 signaling in microglia via intracerebral liposomeencapsulated SB-431542 delivery triggered hemorrhages after tMCAO, demonstrating that TGF $\beta 1 /$ TGFbr2/ALK5 signaling in microglia protects from hemorrhages. Consistent with observations in neonatal rats, depletion of microglia before tMCA0 in P9 $\mathrm{Cx} 3 \mathrm{cr} 1{ }^{\mathrm{GFP} /+} /$ $\mathrm{Ccr} 2{ }^{\mathrm{RFP} /+}$ mice exacerbated injury and induced hemorrhages at $24 \mathrm{~h}$. The effects were independent of infiltration of Ccr2 ${ }^{\mathrm{RFP} /+}$ monocytes into injured regions. Cumulatively, in two species, we show that microglial cells protect neonatal brain from hemorrhage after acute ischemic stroke.

Key words: blood- brain barrier; extracellular matrix; inflammation; middle cerebral artery occlusion; postnatal; TGF $\beta 1$

\section{Significance Statement}

The pathophysiological mechanisms of brain damage depend on brain maturation at the time of stroke. We assessed whether microglial cells preserve neurovascular integrity after neonatal stroke. In neonatal rats, microglial depletion or pharmacological inhibition of TGFbr2/ALK5 signaling in microglia triggered hemorrhages in injured regions. The effect was not associated with additional changes in expression or intracellular redistribution of several tight junction proteins or collagen IV degradation induced by stroke. Consistent with observations in neonatal rats, microglial depletion in neonatal mice exacerbated stroke injury and induced hemorrhages. The effects were independent of infiltration of monocytes into injured regions. Thus, microglia protect neonatal brain from ischemia-induced hemorrhages, and this effect is consistent across two species.

\section{Introduction}

The incidence of perinatal stroke is similar to that in the elderly (Lynch and Nelson, 2001; Kirton and Deveber, 2013). Perinatal

\footnotetext{
Received Jan. 9, 2015; revised Jan. 10, 2016; accepted Jan. 13, 2016.

Author contributions: Z.S.V. designed research; D.F.-L., J.F., A.L.K., N.D., E.B., and F.S. performed research; D.F.L., J.F., E.B., F.S., S.L.L., and Z.S.V. analyzed data; D.F.-L. and Z.S.V. wrote the paper.

The work was supported by R01 NS55915 to Z.S.V., R01 NS44025 to Z.S.V., R01 NS76726 to Z.S.V. and A.L.K., R21 NS080015 to Z.S.V., Ramón Areces Foundation, Madrid, Spain to D.F.-L., Swiss National Science Foundation 310030_162583 to S.L.L., and The American Heart Association P0ST10980003 to D.F.-L. The authors thank Patrick Rugo for technical help.

The authors declare no competing financial interests.

Correspondence should be addressed to Dr. Zinaida S. Vexler, University California-San Francisco, Department of Neurology, 675 Nelson Rising Lane, San Francisco, CA 94158-0663. E-mail: Zena.Vexler@ucsf.edu.
}

stroke leads to significant morbidity and long-term neurological deficits. It has become clear that brain immaturity at the time of injury plays a key role in the pattern of brain damage in humans, but the underlying mechanisms of the differing pathophysiology of perinatal and adult stroke are far from being understood (Fernández-López et al., 2014). Recent studies showed that hemorrhagic transformation of infarction is the leading mechanism of hemorrhagic stroke in term and late preterm neonates (Armstrong-Wells et al., 2009; Bruno et al., 2014), but the underlying mechanisms are poorly defined. 
Vascular degeneration and malfunction are important contributors to stroke. In adults, ischemia-reperfusion disrupts both structural morphology of the blood-brain barrier (BBB) and finely tuned interactions between endothelial cells, vascular basal lamina, pericytes, and astrocytes, allowing neurotoxic plasma components into the brain. Depending on initial stroke severity (i.e., length and extent of perfusion deficits), disruption of the BBB can be rapid and biphasic (Yang and Rosenberg, 2011) or gradual and delayed (Knowland et al., 2014), with disruption of both the transcellular and paracellular permeability mechanisms. Lengthy periods of perfusion deficits followed by reperfusion lead to hemorrhagic transformation (Jickling et al., 2014). These pathophysiological events, which are closely associated with the increased recruitment and infiltration of circulating leukocytes, trigger local inflammation in the brain and contribute to further BBB breakdown and endothelial cell degeneration (Denes et al., 2010). Endothelial cells exposed to locally produced cytokines become reactive and actively facilitate the recruitment of circulating leukocytes through upregulation of adhesion molecules at the luminal vessel side. Adherent and infiltrated leukocytes release neurotoxic inflammatory mediators and reactive oxygen species (ROS) and activate glial cells, further damaging vascular integrity (Iadecola and Anrather, 2011). Stroke-induced neuroinflammatory processes, including microglial responses, also differ between neonatal brain and adult brain, and strategies aimed to prevent or reduce inflammatory damage in adults may be ineffective or deleterious in newborns (Fernández-López et al., 2014).

Until recently, disruption of the BBB in a postischemic neonatal brain was assumed, with little evidence for or against such a notion. We identified major differences in functional $\mathrm{BBB}$ responsiveness to ischemia-reperfusion between neonates and adults by showing that leakage of large intravascular tracers in the neonatal rat brain is significantly lower than in the adult brain $24 \mathrm{~h}$ after transient middle cerebral artery occlusion (tMCAO) and that several factors, including distinct mechanisms of endothelial cell activation, structure of the extracellular matrix (ECM), and neutrophil-endothelial interactions, account, at least in part, for the differences in BBB functional integrity observed between the two ages (Fernández-López et al., 2012).

Activated microglial cells have been traditionally considered injurious in the postischemic brain due to production of inflammatory mediators, ROS, and other toxic molecules (Wang et al., 2007). However, more recent data suggest that microglia may have a dual role after stroke, injurious (Monje et al., 2003) or beneficial (Lalancette-Hébert et al., 2007). Microglial phenotypes are heterogeneous, and the origins of resident microglia and infiltrated monocytes are distinct (Ginhoux et al., 2010), producing separate effects in stroke. Data are also emerging that microglial phenotypes during fetal and postnatal brain development differ from those in the adult and that microglial cells have unique roles in the postnatal brain (Paolicelli et al., 2011; Butovsky et al., 2014).

We previously showed that depletion of microglia enhances neuroinflammation and exacerbates injury in neonatal rats subjected to tMCAO (Faustino et al., 2011). In this study, we asked whether microglial cells have direct effects on neurovascular integrity after neonatal stroke. We demonstrate that microglial depletion adversely affects vascular density and increases vascular permeability and the incidence of intracerebral hemorrhages in acutely injured regions, and that inhibition of TGF $\beta 1$ signaling selectively in microglia recapitulates hemorrhage induction in a neonatal rat tMCAO model. We then demonstrate that the effects are not species-specific and that microglia also protect the neonatal postischemic mouse brain from hemorrhages.

\section{Materials and Methods}

All animal experiments were approved by the Institutional Animal Care and Use Committee of the University of California-San Francisco.

Depletion of microglial cells was accomplished by intracerebral administration of liposomes with encapsulated clodronate (dichloromethylene bis-phosphonate, Clod-lip) to P5 rats of either sex, as we previously reported (Faustino et al., 2011). Liposomes containing PBS (PBS-lip) served as vehicle. Density of microglial cells was determined in injured and in matching contralateral regions in all untreated, PBS-lip-treated, and Clod-treated rats. Microglial depletion in Clod-lip-treated rats was defined as at least $85 \%$ reduction in microglial density in injured regions compared with the corresponding injured regions of untreated rats $24 \mathrm{~h}$ after tMCAO. Clod-lip-treated rats with $>15 \%$ microglial density were excluded from the study (Faustino et al., 2011).

Transient $3 \mathrm{~h}$ MCAO was induced in unsexed P7 rats as we previously described (Derugin et al., 2005).

Transient $3 \mathrm{~h} \mathrm{MCAO}$ was induced in unsexed P9-P10 Cx3cr1 ${ }^{\mathrm{GFP} /+} /$ $\mathrm{Ccr} 2^{\mathrm{RFP} /+}$ mice using the surgical procedure we previously described (Woo et al., 2012). The $\mathrm{Cx} 3 \mathrm{cr} 1^{\mathrm{GFP} /+} / \mathrm{Ccr} 2^{\mathrm{RFP} /+}$ mouse line was established by Dr. Charo at the Gladstone Institute at the University of California-San Francisco (Saederup et al., 2010); founders for the colony were kindly provided to us by Dr. Katerina Akassoglou at the Gladstone Institutes at the University of California-San Francisco.

Histological analysis was performed in perfusion-fixed, postfixed, and cryoprotected flash-frozen brains that were sectioned on a cryostat (12$\mu \mathrm{m}$-thick serial sections, $500 \mu \mathrm{m}$ apart). Brain injury was determined in six coronal Nissl-stained sections.

Immunofluorescence image acquisition and 3D data analysis of fluorescence data were performed in rats in adjacent brain sections incubated in blocking solution ( $10 \%$ normal goat serum, $0.1 \%$ Triton X-100 in PBS $1 \times, 1 \mathrm{~h}$, room temperature) overnight at $4^{\circ} \mathrm{C}$ with primary antibodies [rabbit anti-Ibal 1:500, Wako; rabbit anti-collagen IV, 1:1000, Abcam; mouse anti-rat RECA-1 1:200, ABD Serotec; activated caspase-3 (AC3), 1:500, Cell Signaling Technology; mouse anti-rat GFAP 1:500, BD Biosciences; rabbit anti-rat TGF $\beta 1,1: 500$, Torrey Pines; NeuN, 1:100, Millipore Bioscience Research Reagents], followed by appropriate secondary antibodies, isolectin-B4 (IB4, 1:100, Invitrogen) and DAPI. Confocallike $Z$-stacks ( $25 \times$ oil objective, $10 \mu \mathrm{m}$ thick, $1 \mu \mathrm{m} Z$ step) were acquired using a Zeiss microscope equipped with the confocal-like Optigrid devise and Volocity software (Improvision) (Fernández-López et al., 2012). Vascular density was quantified in six fields per view (FOV) per region per brain using automated threshold protocols for object detection. Mean and sum of vessel volume, length, and number were calculated in a standard size voxel. Density of microglia/macrophages was calculated by subtracting RECA- $1^{+}$object volume (vessels) from IB4 ${ }^{+}$object volume (vessels + microglia/macrophages). The number of cells that express activated caspase- 3 colocalizing with RECA- $1^{+}$vessels was quantified manually. The number of string vessels (RECA- $1^{-} / \mathrm{Col}-\mathrm{IV}^{+}$vessels) was obtained by subtraction of RECA- ${ }^{+}$objects from Col-IV ${ }^{+}$objects. Volume data were expressed as the percentage of total sampled volume. Similar staining protocols, image acquisition, and analysis were used in the mouse brain. The numbers of $\mathrm{GFP}^{+}$microglia and $\mathrm{RFP}^{+}$monocytes were calculated. The number of infiltrated monocytes not touching Glut ${ }^{+}$vessels was determined.

Intracerebral hemorrhages in the rat brain parenchyma were visualized by FITC immunofluorescence or in $\mathrm{DAB} / \mathrm{H}_{2} \mathrm{O}_{2}$-stained sections counterstained with Nissl. The total number of hemorrhages was quantified in the ipsilateral and contralateral hemispheres in 4 serial sections per brain (500 $\mu \mathrm{m}$ apart), covering the rostrocaudal extent of the infarct. Intravascular red blood cells were excluded from analysis. Area covered by FITC-positive hemorrhages was measured using Volocity software, the total number of hemorrhages and the number of larger size hemorrhages, with surface area larger than $>10,000 \mu \mathrm{m}^{2}$, were counted, and the data were presented as total sum of hemorrhages. The size of DABpositive hemorrhages was determined as the length of the longest axis in 4 serial sections per rat brain ( $500 \mu \mathrm{m}$ apart) and 6 serial sections per 
mouse brain. The total number of hemorrhages, the number of parenchyma hemorrhages, and the number of hemorrhages $>50 \mu \mathrm{m}$ in rats and $>25 \mu \mathrm{m}$ were determined using a Nikon microscope.

BBB permeability to intravenous fluorescent tracers was determined in rat pups using TRITC-conjugated $70 \mathrm{kDa}$ dextran injected into the jugular vein $23 \mathrm{~h}$ after reperfusion followed by transcardial perfusion $1 \mathrm{~h}$ later (Fernández-López et al., 2012) and using same procedure following intrajugular injection of Alexa-647-conjugated albumin in mouse pups.

In situ detection of superoxide production was determined using cellpermeable dye hydroethidine (DHE, $5 \mathrm{mg} / \mathrm{kg}$, i.p.) administered $3 \mathrm{~h}$ before death, followed by perfusion-fixation, as we previously described (Faustino et al., 2011).

Whole-brain lysates were prepared from injured and matching contralateral regions by homogenization in $1 \times$ lysis buffer (Cell Signaling Technology) containing protease and phosphatase inhibitors (Roche). Injury was confirmed by the presence of spectrin cleavage (anti-spectrin, 1:2000) on same Western blot. Protein expression was determined using rat anti-collagen IV $\alpha-1$ (1:1000, Sato), rabbit anti-claudin-5 (1:500, Invitrogen), mouse anti-occludin (1:500, Invitrogen), rabbit antiSMAD2/3 (1:500, Millipore), rabbit anti-pSMAD2 (1:500, Millipore), and mouse anti-spectrin (1:2000, Millipore) diluted in blocking buffer (5\% milk in $0.2 \%$ Tween $20 / \mathrm{TBS}, 4^{\circ} \mathrm{C}$ overnight). Results were normalized to expression of actin (mouse anti-actin, 1:5000, Sigma-Aldrich).

Subcellular fractions, including cytosolic, membranous, nuclear, and cytoskeletal fractions, were extracted from brain tissue using ProteoExtract Subcellular Proteome Extraction Kit (Calbiochem) according to the manufacturer's instructions. Protein was concentrated by incubation in 4 volumes of ice-cold acetone at $-20^{\circ} \mathrm{C}$ for $1 \mathrm{~h}$ followed by centrifugation at $14,000 \times \mathrm{g}$ for $10 \mathrm{~min}$ and resuspension in a smaller volume of rehydration lysis buffer containing $3 \mathrm{~m}$ urea, $1 \mathrm{~mm}$ DTT, 5\% CHAPS, and 5\% SDS. The identity of each fraction was confirmed by Western blot using anti-MKK3 (cytosolic fraction [CF], Cell Signaling Technology), anti-N-cadherin (membrane/organelle fraction [MF], Epitomics), anti-histone $\mathrm{H} 1$ (nuclear fraction, 1:1000, Santa Cruz Biotechnology), and vimentin (actin cytoskeletal fraction [ACF], Cell Signaling Technology). Protein concentration was normalized to actin in individual subcellular fractions.

MMP-9 and MMP-2 gel zymography was performed in whole-brain lysates from injured and matching contralateral regions using $1 \%$ gelatin SDS-PAGE zymography and Type A gelatin from porcine skin (Sigma). The presence of injury was confirmed on Western blot by calpain- and caspase-3-spectin cleavage, as previously described (Faustino et al., 2011). Equal volumes of brain homogenates were diluted in $4 \times$ sample buffer $(0.125$ mm Tris-HCl, pH 6.8; 4\% sucrose; $10 \%$ SDS, $0.003 \%$ bromophenol blue), and proteins were separated electrophoretically under nonreducing conditions. Human neutrophil MMP-9 (Calbiochem) was used as positive control. SDS was removed using Triton X-100, and gels were incubated overnight at $37^{\circ} \mathrm{C}$ in zymography buffer $(10 \mathrm{~mm} \mathrm{CaCl}$, $50 \mathrm{~mm}$ Tris, $50 \mathrm{~mm} \mathrm{NaCl} \mathrm{pH} \mathrm{7.65).} \mathrm{Gels} \mathrm{were} \mathrm{then} \mathrm{stained} \mathrm{with} \mathrm{a} \mathrm{solution}$ containing Coomassie Blue R250, 30\% methanol, and 10\% acetic acid. Densitometric quantification of the lysis regions $(\sim 92 \mathrm{kDa}$ for proMMP-9) was performed using Scion Image and data normalized per amount of protein in each sample. Recombinant MMP-9 and MMP-2 were included to each gel as a standard.

Recombinant human TGF $\beta 1$ ( $\operatorname{rhTGF} \beta 1$ ) was reconstituted in $10 \mathrm{~mm}$ citric acid, $\mathrm{pH} 3.0$, diluted in PBS/0.1\% BSA, and administered $(0.5$ $\mathrm{mg} / \mathrm{kg} /$ injection; intrajugular) twice, $6 \mathrm{~h}$ and $90 \mathrm{~min}$ before death at $24 \mathrm{~h}$ after reperfusion.

SB-431542 was entrapped into the liposomes by a variant of a proliposome method by mixing SB-431542 in propylene glycol $(5 \mathrm{mg} / \mathrm{ml})$ with concentrated solution of DOPC, cholesterol, and DiI in ethanol; adding 1:3 mass of $0.2 \mathrm{M}\left(\mathrm{NH}_{4}\right)_{2} \mathrm{SO}_{4}$ in water to generate the proliposome gel; gel was rapidly diluted into excess saline to form liposomes. Unincorporated SB-431542 was removed by centrifugal wash. Spectrophotometrically, SB-431542 entrapment rate was $\sim 50 \%$; $\sim 0.062$ or $0.25 \mu \mathrm{g} / \mathrm{g}$ rat was delivered intracortical.

Statistical analysis. Data are presented as mean \pm SD or as medians. Normal data were analyzed by ANOVA with post hoc Bonferroni test for multiple groups or paired $t$ test for comparisons between two groups.
Discrete or not normal data were analyzed using the Kruskal-Wallis or the Mann-Whitney tests.

\section{Results}

Depletion of microglial cells does not induce vascular permeability in uninjured regions but adversely affects vessel coverage and increases vascular permeability in injured regions of $\mathrm{P7}$ rats subjected to tMCAO

Considering that the route of peripheral administration of Clodlip, intravenous or intraperitoneal, was shown to deplete different subpopulations of cells of the monocyte lineage in the blood and in peripheral organs (Polfliet et al., 2001; van Rooijen and Hendrikx, 2010), to preferentially target microglial cells, we administered Clod-lip into brain parenchyma. We previously showed that depletion of microglial cells by intracortical Clod-lip injection before tMCAO in P7 rats enhances neuroinflammation and exacerbates acute injury (Faustino et al., 2011). In this study, we asked whether microglial depletion, defined as $<15 \%$ density of remaining microglial cells in injured regions compared with density in injured regions of untreated rats $24 \mathrm{~h}$ after tMCAO, affects vascular integrity in acutely injured regions. Consistent with our previous report (Faustino et al., 2011), compared with PBS-lip-treated rats (Fig. $1 A, B$ ), Clod-lip depleted $\mathrm{Ibal}^{+} /$ $\mathrm{CD} 68^{+}$microglial cells in the penumbra (Fig. $1 C$ ) and the core (Fig. 1D). As expected, based on less active lysosomal component in ramified microglial cells, microglial depletion was more modest in contralateral regions than in injured hemisphere (data not shown). Quantification of microglial depletion is shown in Figure $1 E$. Microglial depletion significantly exacerbated injury at 72 h (Fig. 1F).

Compared with untreated (data not shown) or PBS-liptreated rats (Fig. 1G), volumetric RECA-1 vessel coverage was significantly reduced in injured cortex of Clod-lip-treated rats (Fig. $1 H$ ) $24 \mathrm{~h}$ after tMCAO, including the cumulative vessel volume in injured cortex (Fig. $1 I$ ) and caudate (Fig. $1 J$ ). The overall vessel density was significantly affected by microglial depletion in the injured caudate but not in matching contralateral regions (Fig. $1 K$ ). Vessel loss was more extensive in rats with more effective depletion of microglia in both the cortex and caudate (data not shown). By $72 \mathrm{~h}$ after tMCAO, vessel volume and length remained significantly lower in the injured cortex of Clodlip compared with vehicle-treated rats (data not shown), whereas vessel coverage was similar in contralateral regions in both groups. Numbers of peripheral monocytes were significantly decreased following $24 \mathrm{~h}$ of tMCAO but were similarly affected in Clod-lip-treated, vehicle-treated, and untreated rats (Fig. $1 L$ ).

Essentially no leakage of fluorescently labeled $70 \mathrm{kDa}$ dextran was observed in the cortex or the caudate of untreated neonatal rats (data not shown), or in the vehicle group throughout the injured caudate (Fig. 1M) and cortex (Fig. 1N) $24 \mathrm{~h}$ after tM$\mathrm{CAO}$, consistent with our previous report (Fernández-López et al., 2012). The leakage was limited despite increased vascular degeneration in the ischemic core during that time, likely because of inadequate perfusion of degenerating vessels within the injury regions. However, depletion of microglia led to increased extravascular leakage of $70 \mathrm{kDa}$ dextran in the injured caudate (Fig. $1 O$ ) and cortex (Fig. 1P). Leakages were absent in the contralateral hemisphere in all groups.

Microglial depletion induces hemorrhages after acute tMCAO Microglial depletion significantly increased the incidence of intracerebral hemorrhages $24 \mathrm{~h}$ after reperfusion, as was evident from the presence of extravascular clusters of red blood cells (Fig. 

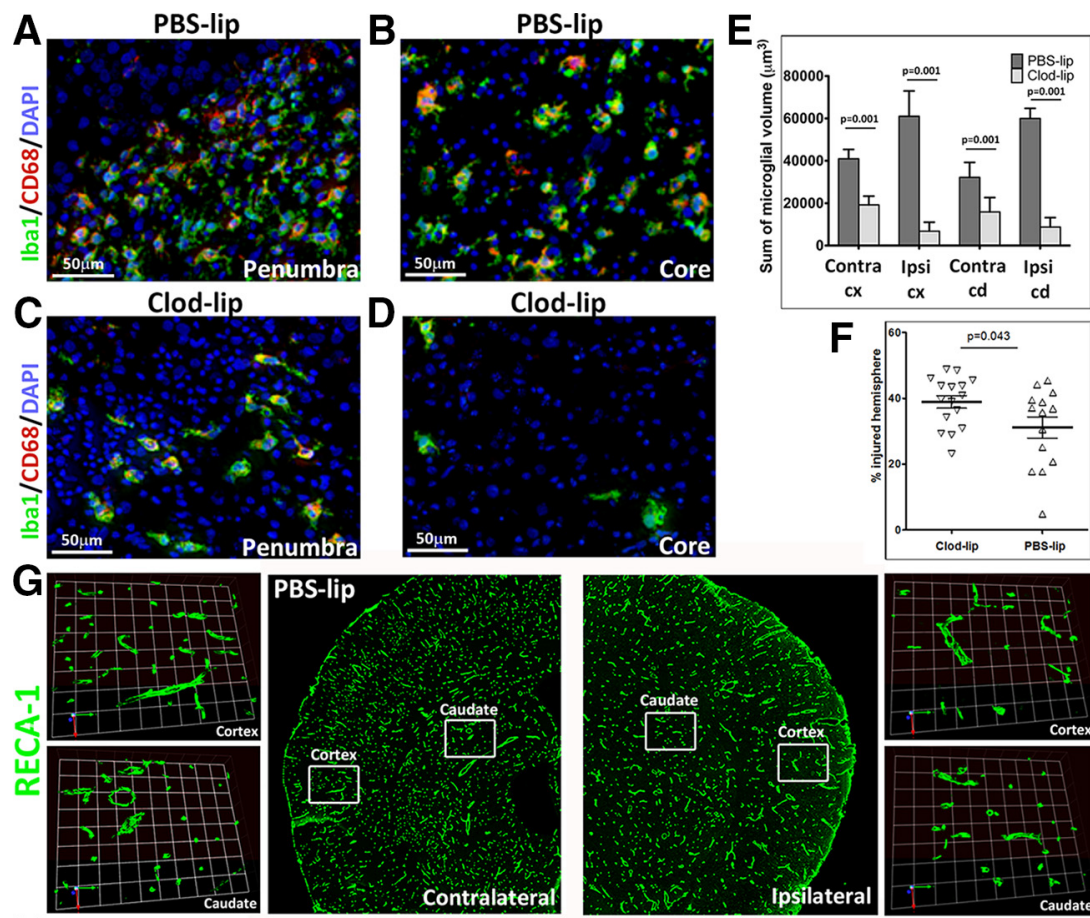

$\mathbf{F}$
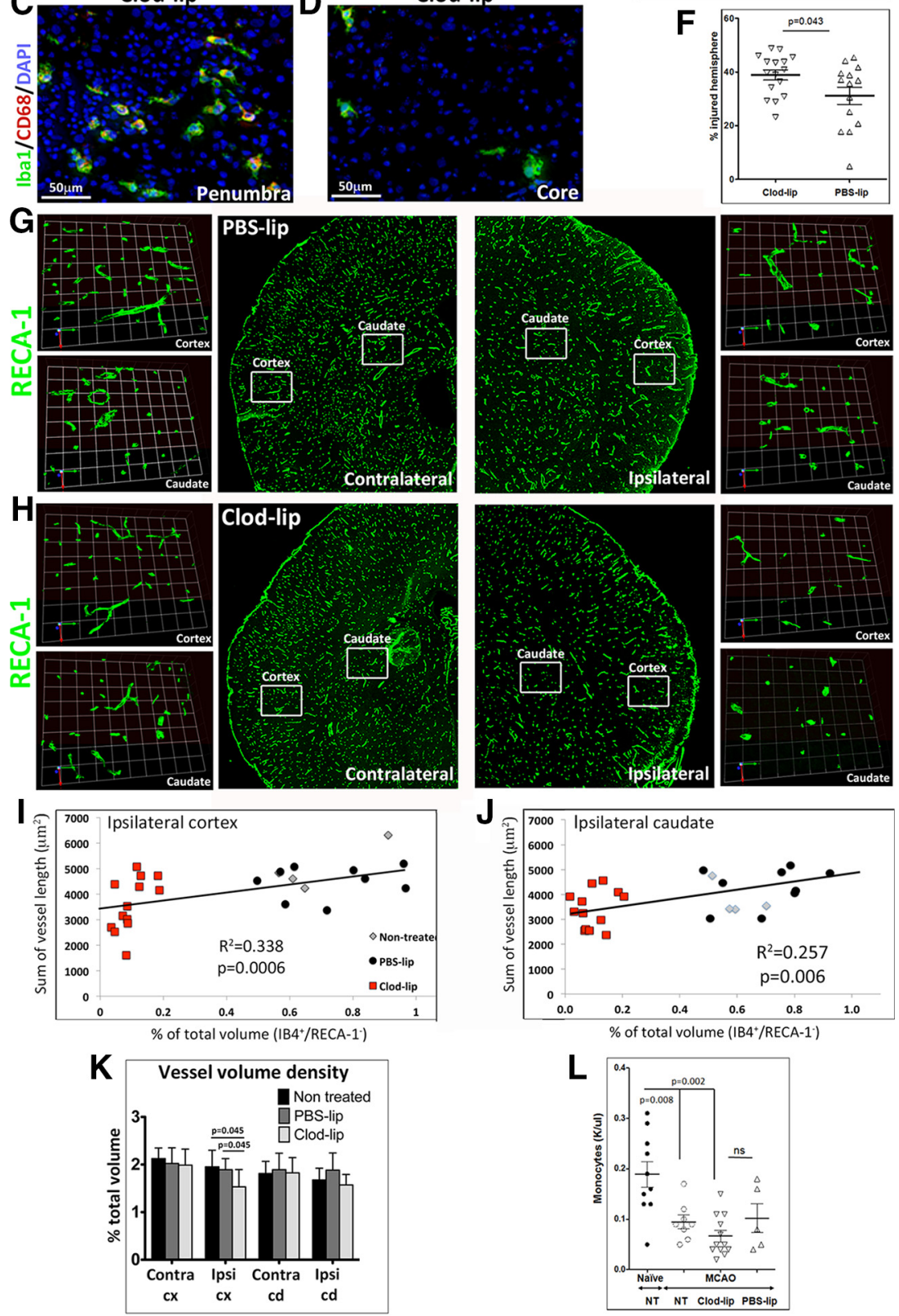

RECA-1/70kDa dextran/DAPI
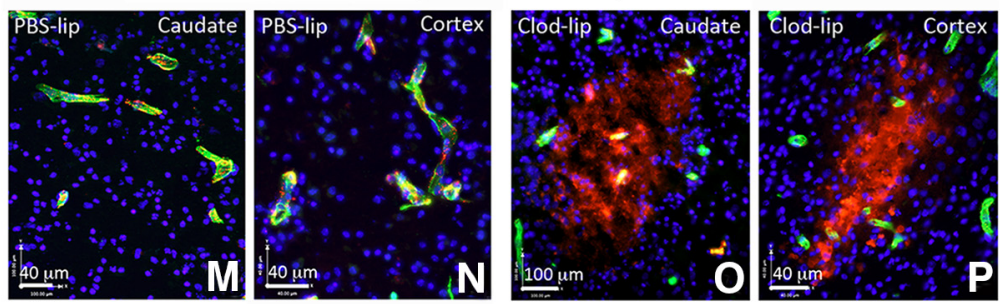

Figure 1. Depletion of microglia compromises vascular integrity $24 \mathrm{~h}$ after tMCAO in P7 rats. $\boldsymbol{A}-\boldsymbol{D}$, Representative images of $\mathrm{Iba}^{+} / \mathrm{CD} 8^{+}$microglial cells in vehicle-treated (PBS-lip; $\left.\boldsymbol{A}, \boldsymbol{B}\right)$ and Clod-lip-treated (Clod-lip; $\left.\boldsymbol{C}, \boldsymbol{D}\right)$ rats. Images are captured in
$2 A, B)$. Hemorrhages of various size were apparent in several injured parenchyma regions, including cortex (Fig. $2 A$ ), caudate (Fig. $2 B$ ), and thalamus (data not shown). Occasional hemorrhages were also seen in the meninges and at the choroid plexus. The number of hemorrhages regardless of size (Fig. 2C) and the number of relatively large hemorrhages (surface area $>10,000 \mu \mathrm{m}^{2}$; Fig. 2D) was significantly increased in Clod-lip-treated rats, but vascular permeability to $70 \mathrm{kDa}$ dextran was seen in both hemorrhagic and nonhemorrhagic vessels, and hemorrhages were seen in nonleaky vessels (Fig. 3 ), suggesting that the mechanisms of BBB permeability and hemorrhages are distinct at least in part. Clod-lip treatment did not increase the incidence of hemorrhages in contralateral regions (Fig. 2C,D) or in otherwise unperturbed rats, ruling out direct effects of Clod-lip on cerebrovascular integrity. The presence of hemorrhages continued through $72 \mathrm{~h}$ after stroke (data not shown).

\section{Microglial depletion exacerbates}

endothelial cell death $24 \mathrm{~h}$ after tMCAO We then asked whether the decreased vascular coverage in rats with depleted microglia results from enhanced endothelial cell death or from diminished levels of growth factors that support cerebral vasculature and promote angiogenesis. tMCAO induced caspase-3dependent endothelial cell death, as was evident from the increased number of endothelial cells expressing cleaved caspase-3 (RECA-1 ${ }^{+} / \mathrm{AC}^{+}{ }^{+}$cells; Fig.

the penumbra regions $(\boldsymbol{A}, \boldsymbol{C})$ and in the ischemic core regions $(\boldsymbol{B}, \boldsymbol{D})$. There is marked reduction in the number of microglial cells in both regions of Clod-lip-treated rat pups. $\boldsymbol{E}$, Quantification of the total microglial cell volume in uninjured contralateral regions (Contra) and in injured cortex $(\mathrm{cx})$ and caudate (cd), showing depleted microglial cell population in animals treated with Clod-lip. $\boldsymbol{F}$, Injury volume $72 \mathrm{~h}$ after tMCAO is significantly larger in rat pups with depleted microglial cells. Shown are data for individual animals. $\boldsymbol{G}, \boldsymbol{H}$, Representative 3D projections from $z$-stacks of RECA- $1^{+}$vessels in cortex and caudate of vehicle-treated treated rats $(\boldsymbol{G})$ and Clod-lip-treated rats $(\boldsymbol{H}) . \boldsymbol{I}, \boldsymbol{J}$, Relationship between density of microglia (IB4 ${ }^{+} /$RECA $^{-}$cells) and vascular density (RECA$1^{+}$) in injured cortex (I) and caudate ( $\boldsymbol{J}$ ). $\boldsymbol{K}$, Vessel volume density is significantly reduced in injured cortex and caudate of Clod-lip-treated rats. $L$, Number of peripheral monocytes is significantly reduced by $\mathrm{TMCAO}$, but the extent of reduction is similar in nontreated (NT), PBS-lip, and Clod-lip groups. Shown are data for individual animals. $\boldsymbol{M}-\boldsymbol{P}$, Representative images showing vascular permeability to $70 \mathrm{kDa}$ TRITCdextran in injured regions of rats injected PBS-lip ( $\boldsymbol{M}$; caudate; $\mathbf{N}$; cortex) and Clod-lip ( $\mathbf{O}$; caudate; $\boldsymbol{P}$; cortex). Significance levels as indicated. 

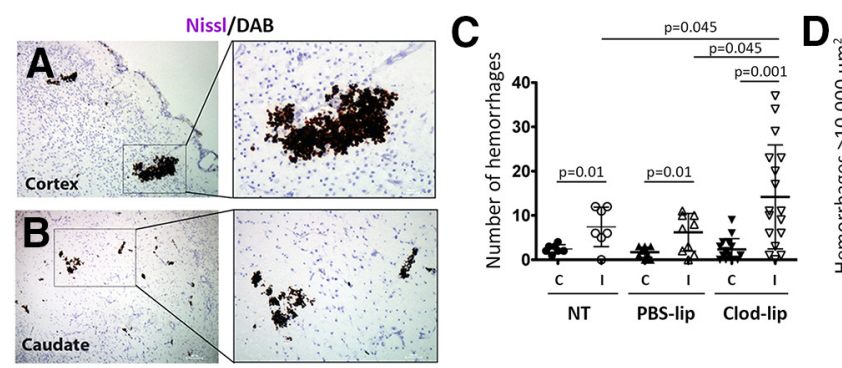

Figure 2. The incidence of intracerebral hemorrhages is increased $24 \mathrm{~h}$ after $\mathrm{TMCAO}$ in rats with depleted microglial cells. $A, B$, Representative images of DAB-positive red blood cells showing the presence of intracerebral hemorrhages in the injured cortex $(\boldsymbol{A})$ and caudate $(\boldsymbol{B})$ of Clod-lip-treated rats. The sections were costained with Nissl. $\boldsymbol{C}, \boldsymbol{D}$, Quantification of the number of hemorrhages in six fluorescently labeled coronal sections. $C$, The total number of intracerebral hemorrhages. D. The number of large hemorrhages $\left(>10,000 \mu \mathrm{m}^{2}\right)$. Shown are data for individual rats. Significance levels as indicated.
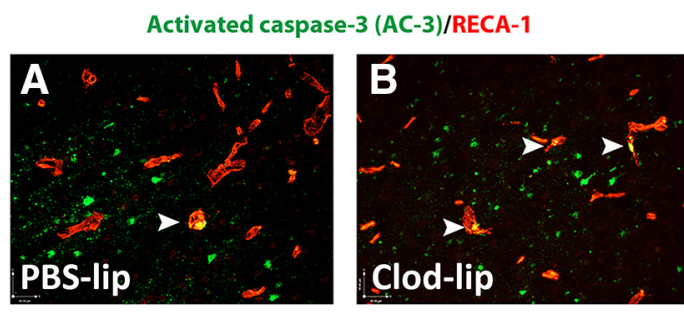

C
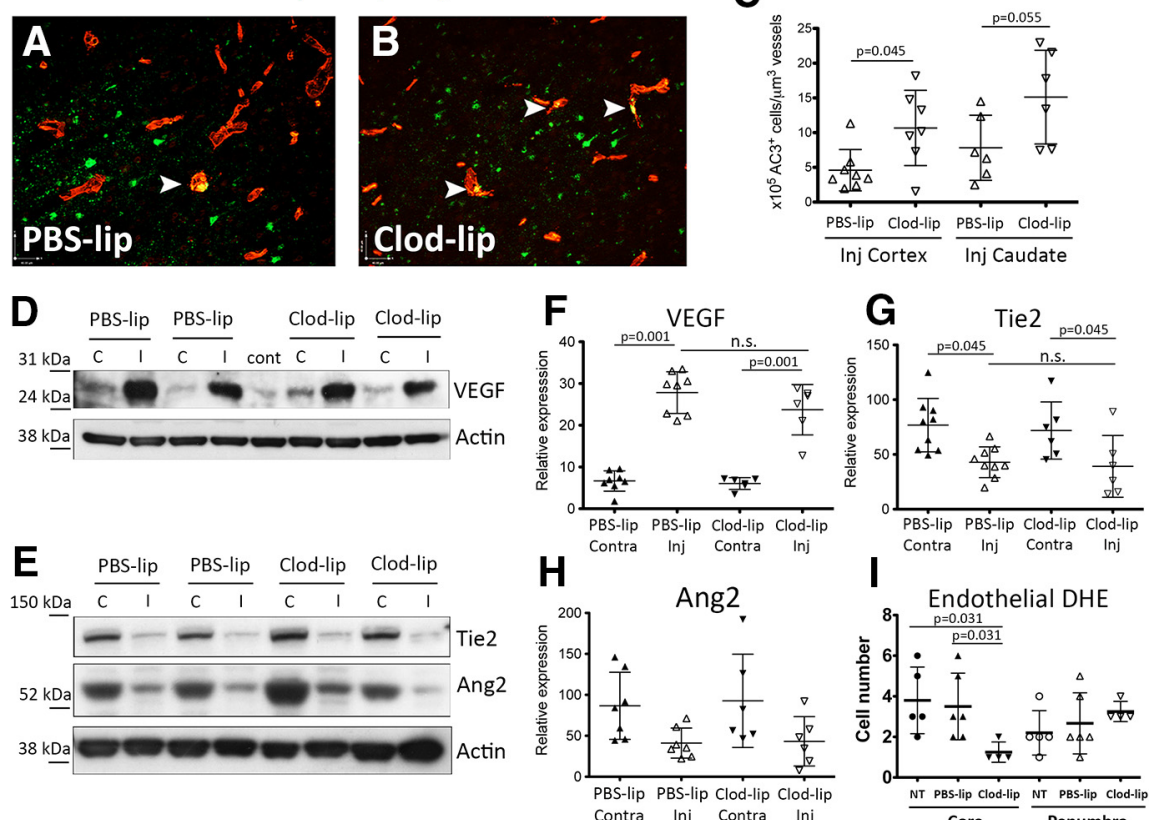

I

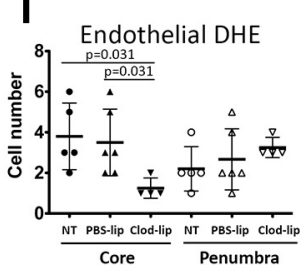

Figure 3. Depletion of microglia worsens endothelial cell apoptosis but does not affect protein expression of proangiogenic mediators $24 \mathrm{~h}$ after tMCAO. $A, B$, Representative images showing colocalization of the apoptosis marker activated caspase-3 (AC3) and the endothelial marker RECA-1 in injured regions of rats treated with PBS-lip (A) or Clod-lip $(\boldsymbol{B})$. $\boldsymbol{C}$, Quantification of the number of apoptotic endothelial cells normalized for vascular density in the injured cortex and caudate. $\boldsymbol{D}, \boldsymbol{F}$, Representative Western blots showing protein expression of proangiogenic mediators VEGF (D) and the Tie2/Ang2 system $(\boldsymbol{F}) . \boldsymbol{E}, \boldsymbol{G}, \boldsymbol{H}$, Densitometric quantification of protein expression of VEGF $(\boldsymbol{F})$, Tie2 (G), and Ang2 $(\boldsymbol{H})$. Data were normalized for actin expression. n.s., Not significant. $I$, Quantification of the number endothelial cells positive for DHE per FOV in the ischemic core and ischemic penumbra at $24 \mathrm{~h}$ after tMCAO.

$3 A, C)$. The number of RECA- $1^{+} / \mathrm{AC}^{+}$cells (arrowheads) was further significantly increased in injured regions of Clodlip-treated rats (Fig. 3B vs Fig. 3A; Fig. 3C). Clod-lip did not induce caspase-3-dependent endothelial cell death in contralateral regions or in uninjured animals.

Considering that oxidative injury can both activate endothelial cells and contribute to endothelial death, we determined superoxide accumulation in the vessels using DHE, a dye that gives fluorescence products during its oxidation by superoxide, as we previously reported (Faustino et al., 2011). The numbers of $\mathrm{DHE}^{+}$cells in IB4 ${ }^{+}$vessels were not significantly different in the penumbra of untreated, PBS-lip-treated, and Clod-lip-treated rats and were significantly lower in the ischemic core in Clod-lip

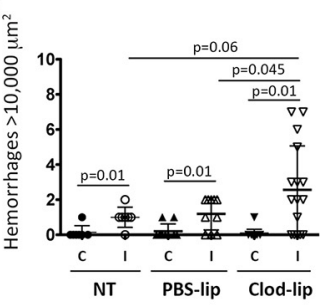

group than in nontreated or PBS-liptreated groups (Fig. 3I; $p=0.031$ ).

The protein levels of VEGF, a growth factor important for vascular signaling, permeability, and angiogenesis (Greenberg and Jin, 2013), were similar in contralateral cortex regardless of treatment, and VEGF expression was significantly and similarly increased in the injured cortex in both groups (Fig. 3D,E). The protein levels of Ang1 and its receptor Tie2, key regulators of vascular stabilization and maturation (Hansen et al., 2008), were also similarly affected by injury in vehicle- and Clod-lip-treated rats (Fig. $3 F-H)$, suggesting that enhanced endothelial death and reduced vascular coverage are unlikely because of insufficient VEGF support or halted angiogenesis at this early injury stage.

Vascular permeability changes induced by microglial depletion are not due to collagen IV degradation by MMP-9

Considering that in the adult hemorrhagic transformation after stroke occurs, in part, due to activation of several proteases (Gidday et al., 2005; Rosell et al., 2008), we tested the effects of microglial depletion on activation of a major inducible Col-IV degrading protease, MMP-9. As evident from gel zymography, the amount of active MMP-9 was significantly increased in injured tissue of untreated and PBS-lip-treated neonatal rats (Fig. $4 A, C$ ) but was below detectable levels in contralateral tissue $24 \mathrm{~h}$ after reperfusion. Depletion of microglia largely abolished expression of active MMP-9 (Fig. $4 A, C$ ). At $72 \mathrm{~h}$ after reperfusion, levels of active MMP-9 remained elevated in injured regions of $\sim 50 \%$ of untreated and vehicle-treated rats but were below detectable levels in all Clod-lip-treated rats (Fig. 4B,D). These results suggest that activated microglia are an important source of MMP-9 in the postischemic neonatal brain.

Markedly reduced MMP-9 resultant from microglial depletion after tMCAO did not affect the pattern of degradation of the most abundant Col-IV isoform in brain vascular basement membrane, Col-IV $\alpha 1$ (Fig. 4E-I). Compared with contralateral regions, protein expression of the integrant Col-IVa1 isoform (230 kDa band) was decreased, in parallel to accumulation of the lower molecular weight Col-IVal fragment ( $55 \mathrm{kDa}$ band) (Fig. 4G-I). Immunofluorescence analysis showed that Col-IV coverage of hemorrhagic vessels of Clod-lip-treated rats (Fig. $4 F$ ) was unaltered compared with nonhemorrhagic vessels in rats with depleted or unmanipulated microglia (Fig. 4E). Expression of active MMP-2, a constitutive matrix metalloprotease that also degrades Col-IV, was unchanged by microglial depletion at 24 or $72 \mathrm{~h}$ (data not shown). Thus, reduction of MMP-9 caused by microglial deple- 
tion may be overshadowed by the presence of MMP-2 and other Col-IV degrading proteases produced by other sources.

String vessels, or acellular portions of vessels comprised of degraded Col-IV sheaths without the underlying endothelium, were present throughout the injured regions of both groups $72 \mathrm{~h}$ after neonatal stroke (Fig. 4J, arrows pointing to missing endothelium), but the number of string vessels $\left(\mathrm{Col}-\mathrm{IV}^{+} / \mathrm{RECA}^{-}{ }^{-}\right.$) was significantly higher in rats with depleted microglia (Fig. 4L). Vessels undergoing conversion to string vessels (e.g., partial loss of vascular endothelium) were evident in association with local hemorrhages (Fig. $4 K$ ). Cumulatively, these data suggest that degenerative alterations of the brain endothelium, rather than Col-IV degradation, account for the increased vascular permeability and hemorrhagic transformation in rats with depleted microglia.

\section{The effects of microglial depletion on the expression and subcellular distribution of endothelial tight junction proteins}

Disorganization and consequent diminished tightness of the tight junction (TJ) proteins contributes to BBB leakiness after stroke (Knowland et al., 2014). Our comparative study of BBB integrity following acute tMCAO in neonatal and adult rats showed that expression of occludin, ZO-1, and claudin-5 is better preserved in neonates, consistent with the better preserved $\mathrm{BBB}$ integrity (Fernández-López et al., 2012). Here we asked whether microglial depletion affects expression and intracellular distribution of two transmembrane TJ proteins, occludin and claudin-5.

Claudin-5 expression determined in whole tissue lysates was unaffected at 24 or $72 \mathrm{~h}$ after tMCAO in rats with unperturbed or depleted microglia (Fig. $5 A$, total, $B$; data for $72 \mathrm{~h}$ not shown). In contrast, occludin expression determined in whole tissue lysates was reduced at $24 \mathrm{~h}$ (Fig. 5C, total, $D$ ) and restored to normal levels at $72 \mathrm{~h}$ after tMCAO in vehicletreated rats (data not shown). However, diminished occludin expression was sustained (Fig. $5 C$, total, $D$ ) in rats with depleted microglia, with no restoration of protein levels at $72 \mathrm{~h}$ (data not shown). Cellular subfractionation experiments performed to investigate whether lack of microglial cells affects occludin and claudin-5 distribution within the cells showed that $\mathrm{tMCAO}$ induces redistribution of both occludin and claudin-5 in different cell compartments. The presence of both proteins was reduced in the cytoskeletal-associated fraction cor-
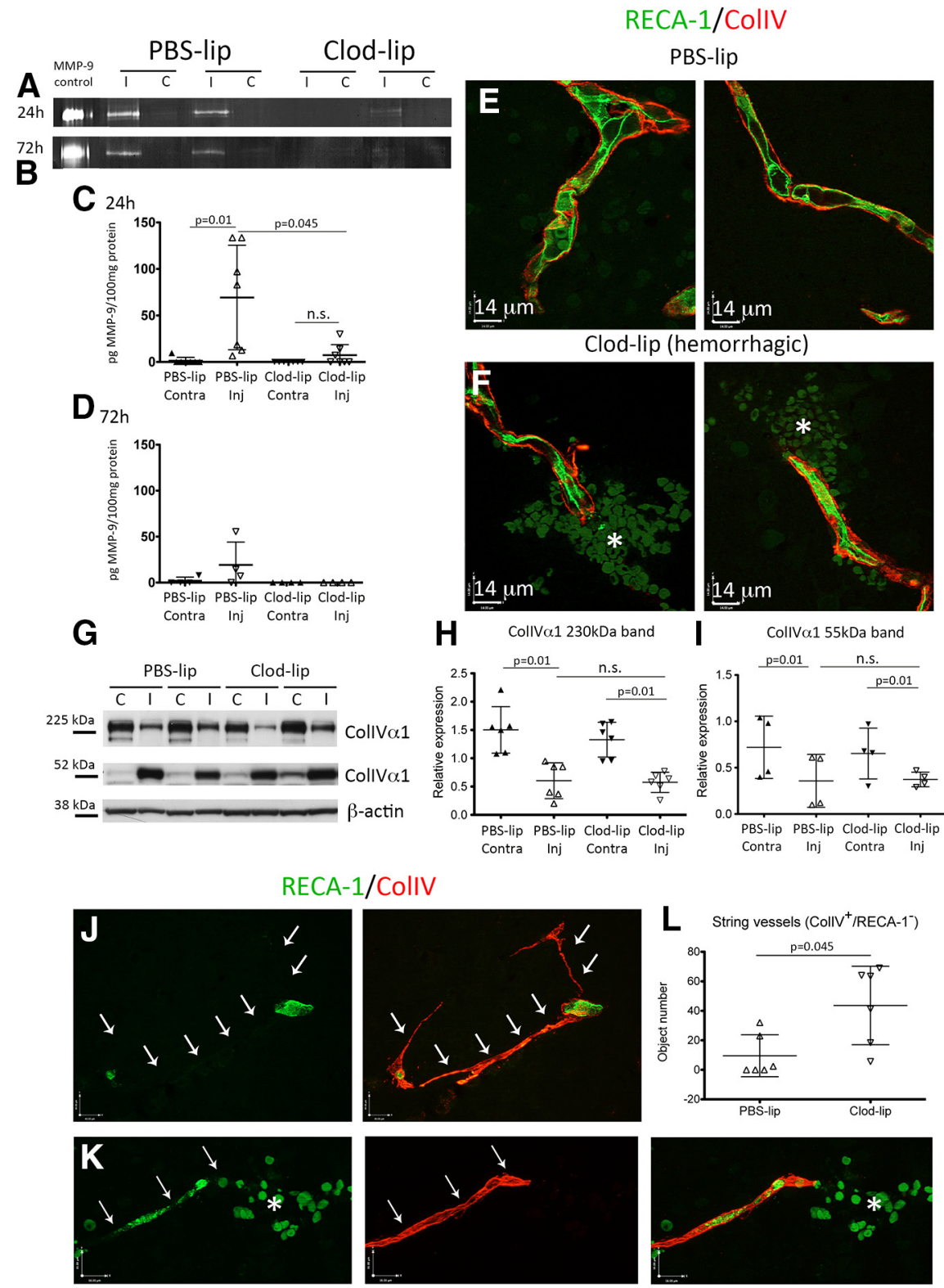

Figure 4. Intracerebral hemorrhages induced by microglial depletion are not associated with increased Col-IV degradation. $A$, $\boldsymbol{B}$, Representative gel zymograms showing MMP-9 activity at $24 \mathrm{~h}(\boldsymbol{A})$ and $72 \mathrm{~h}(\boldsymbol{B})$ after $\mathrm{MCA0}$. C, D, Quantification of MMP-9 activity $24 \mathrm{~h}(\boldsymbol{C})$ and $72 \mathrm{~h}(\boldsymbol{D})$ after tMCA0. Activity is shown as units $\mathrm{pg}$ MMP-9/100 $\mu \mathrm{g}$ protein. The presence of active MMP-9 is significantly lower/absent in Clod-lip-treated rats. $\boldsymbol{E}, \boldsymbol{F}$, Col-IV coverage of RECA- ${ }^{+}$vessels in PBS-lip-treated rats ( $\boldsymbol{E}$; two individual vessels and Clod-lip-treated rats ( $\boldsymbol{F}$; two individual vessels) $24 \mathrm{~h}$ after reperfusion. Asterisks indicate hemorrhages. Col-IV coverage is similar in hemorrhagic $(\boldsymbol{F})$ and nonhemorrhagic $(\boldsymbol{E})$ vessels. $\mathbf{G}-\mathbf{I}$, Representative examples of Col-IV $\alpha 1$ expression on Western blots. High molecular weight band (230 kDa) corresponds to an integrant Col-IV $\alpha 1$ monomer, and a lower molecular weight band ( $55 \mathrm{kDa}$ ) corresponds to one of degradation fragments of collagen-IV $\alpha 1$. C, Contralateral hemisphere; I, ipsilateral hemisphere. Densitometric analysis of expression of an integrant Col-IV monomer $(\boldsymbol{H} ; 230 \mathrm{kDa})$ and of a $55 \mathrm{kDa}$ degradation fragment $(\boldsymbol{I})$ shows $\mathrm{Col}-\mathrm{IV}$ degradation in injured regions, with no significant differences in the patterns of expression or degradation after microglial depletion. The data are normalized to a common control sample used in all gels. J, Representative images of string vessels (RECA- ${ }^{-} / \mathrm{COI}^{-} \mathrm{IV}^{+}$) $72 \mathrm{~h}$ after tMCA0. $\boldsymbol{K}$, Representative image of hemorrhage (asterisk) associated with a degenerating vessel (RECA-1). $L$, Quantification of the number of string vessels (RECA- $\left.1^{-} / \mathrm{COI}^{-I V}{ }^{+}\right) 72 \mathrm{~h}$ after $\mathrm{MCA}$. There is increased endothelial degradation in rats with depleted microglia. Green represents RECA-1. Red represents Col-IV. Significance levels as indicated. n.s., Not significant.

responding to integrant $\mathrm{TJ}$ (Fig. 5, ACF) and increased in the cytosolic and/or membrane fractions (Fig. 5, CF, MF), indicating that these proteins are removed from the TJ, consistent with that previously described in the adult (Liu et al., 2012). However, the patterns of subcellular redistribution were similar in vehicle- and Clod-lip-treated rats (Fig. 5), indicating a 


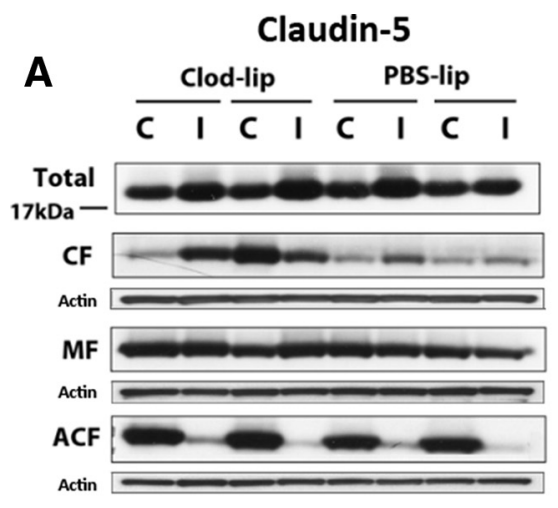

B

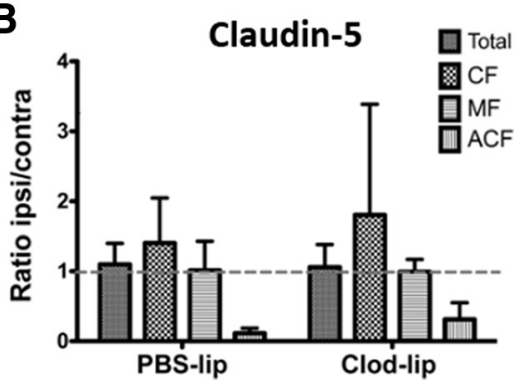

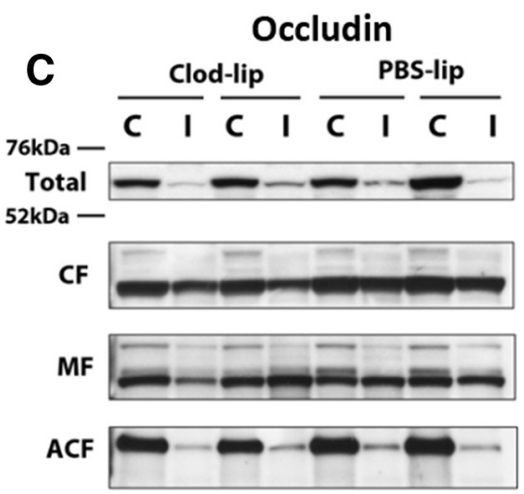

D

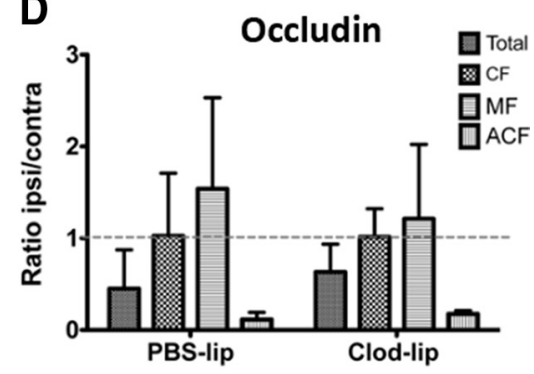

Figure 5. Depletion of microglia does not significantly affect subcellular redistribution of tight junction proteins induced by neonatal stroke in $24 \mathrm{~h}$ after tMCA0. $\boldsymbol{A}, \boldsymbol{C}$, Representative Western blots showing the presence of the TJ proteins claudin-5 $(\boldsymbol{A})$ and occludin ( $\boldsymbol{C}$ ) in whole tissue lysates and in subcellular fractions (cytosolic (F, membrane MF, and cytoskeletal ACF). $\boldsymbol{B}, \boldsymbol{D}$, Densitometric quantification showing the effect of tMCA0 and microglial depletion on the expression of claudin-5 (B) and occludin (D) in whole tissue lysates and in individual subcellular fractions. Expression of both proteins was examined in the same samples and was normalized to actin in individual subcellular fractions. Data are expressed as the ratio of ipsilateral/contralateral regions.

similar extent of alteration of integrant TJs in both groups, at least at $24 \mathrm{~h}$ after stroke.

\section{Microglial deletion affects TGF $\beta 1 /$ ALK5 signaling $24 \mathrm{~h}$ after tMCAO}

TGF $\beta 1$ plays multiple roles in healthy and diseased brain, including muting neuroinflammation, stabilization of the vascular niche, and preventing from hemorrhagic transformation after stroke (Munger and Sheppard, 2011; Gliem et al., 2012). We asked whether TGF $\beta 1$ signaling is disturbed in acutely injured neonatal brain deprived of microglia. In adult focal stroke, multiple brain cell types constitutively express TGF $\beta 1$ and upregulate TGF $\beta 1$ (Pál et al., 2012; Cekanaviciute et al., 2014; Pál et al., 2014) and downstream signaling (Pál et al., 2014). Similar to that in adult stroke, in neonates subjected to tMCAO, neurons ubiquitously express TGF $\beta 1$ in uninjured brain regions (Fig. 6), but TGF $\beta 1$ is no longer detectable in neurons within injured regions. Vascular expression of TGF $\beta 1$ was seen in both uninjured and injured regions but, in contrast to adults, where astrocytes upregulate TGF $\beta 1$ during acute and subchronic injury (Doyle et al., 2010; Cekanaviciute et al., 2014; Pál et al., 2014), levels of TGF $\beta 1$ expression were below detectable in reactive astrocytes in our study. TGF $\beta 1$ expression was upregulated in activated microglia in injured cortex and caudate (Fig. 6A). Accordingly, in rats with depleted microglia, the vast majority of TGF $\beta 1$-expressing cells were endothelial cells. We tested whether microglial depletion affects SMAD2/3 protein expression, SMAD2/3 phosphorylation, and TGF $\beta 1 / A L K 5$-induced pSMAD2/3-mediated downstream signaling in injured regions. tMCAO significantly reduced SMAD2/3 expression in injured regions, but the magnitude of reduction was unaffected by microglial depletion (Fig. $6 B, C$ ). SMAD2/3 phosphorylation was significantly reduced in whole tissue lysates from injured regions of Clod-lip-treated rats (Fig. $6 B, D, F)$. The loss of SMAD2/3 phosphorylation in relation to the loss of SMAD2/3 expression was not assessed, as Western blot-based measurements do not allow addressing whether reduced SMAD phosphorylation occurs in cells with reduced SMAD2/3 expression. SMAD2/3 phosphorylation was significantly reduced in the nuclear fraction from injured cortex in the absence of microglial cells (Fig. 6D,F), fraction identified as histone $\mathrm{H} 1$-enriched fraction (Fig. 6E). Therefore, microglial depletion diminishes TGF $\beta 1 /$ ALK- 5 signaling to the nucleus in the acutely injured neonatal brain. Immunofluorescence that we used to identify cell types expressing pSMAD2/3 showed that $\mathrm{NeuN}^{+}$neurons abundantly express $\mathrm{pS}$ $\mathrm{MAD} 2 / 3$ in contralateral regions (Contra; Fig. $6 G$ ) and in uninjured regions within ipsilateral hemisphere (Ipsi; Fig. 6G), but SMAD2/3 phosphorylation is lost in neurons with shrunken or disintegrated nuclei (Ipsi; Fig. 6G). In contrast, SMAD2/3 phosphorylation is increased in activated microglial cells (Fig. 6G,H). IB4 ${ }^{+}$vessels express pSMAD2/3 in injured (Fig. $6 H$ ) and uninjured (Fig. $6 G, H$ ) regions.

To test whether hemorrhage induction associated with the absence of microglial TGF $\beta 1$ signaling can be reversed by TGF $\beta 1$ supplementation, we intravenously administered rhTGF $\beta 1$ to Clod-lip-treated rats at 18 and $22 \mathrm{~h}$ after reperfusion (human and rat TGF $\beta 1$ have a 99\% homology in the amino acid sequence) and confirmed that the plasma levels of TGF $\beta 1$ at the time of death at $24 \mathrm{~h}$ were several-fold higher in rhTGF $\beta 1$-treated rats than in nontreated rats (Fig. $6 I$, inset). Injury volume in rats with depleted microglia was not affected at $24 \mathrm{~h}$ after reperfusion by the systemic rhTGF $\beta 1$ administration: $53 \pm 6 \%$ of ipsilateral hemisphere in rats treated with Clod-lip and $\operatorname{rhTGF} \beta 1(n=11)$ compared with $58.1 \pm 3 \%$ in Clod-lip-treated rats $(n=4)$. The number of intraparenchymal hemorrhages regardless of size was unaffected by the increased circulating levels of rhTGF $\beta 1$ (Fig. $6 I$ ). There were also no differences in the distribution of hemorrhages of different size (data not shown). These data indicate that increased circulating TGF $\beta 1$ levels do not substitute for the TGF $\beta 1$ signaling derived from activated microglia after acute neonatal stroke.

\section{Selective inhibition of TGFbr2/ALK5 signaling in activated microglial cells induces hemorrhagic transformation after neonatal arterial stroke}

To directly test whether microglial TGF $\beta$ signaling protects neonatal brain from ischemia-induced hemorrhages, we delivered a specific TGFbr2/ALK5 inhibitor, SB-431542, into microglial cells via intracortical injection of liposome-encapsulated SB-431542 before tMCAO. We fluorescently labeled SB-431542-lip with DiI to trace liposomes in the brain and confirmed that $\mathrm{DiI}^{+} / \mathrm{SB}$ $431542^{+}$liposomes accumulate almost exclusively in activated IB ${ }^{+}$microglia (Fig. $7 B$, arrowheads) or $\mathrm{Ibal}^{+}$microglia (Fig. $7 C$, yellow arrows), rather than in other brain cell types. Consistent with our previous observations (Faustino et al., 2011), only a 

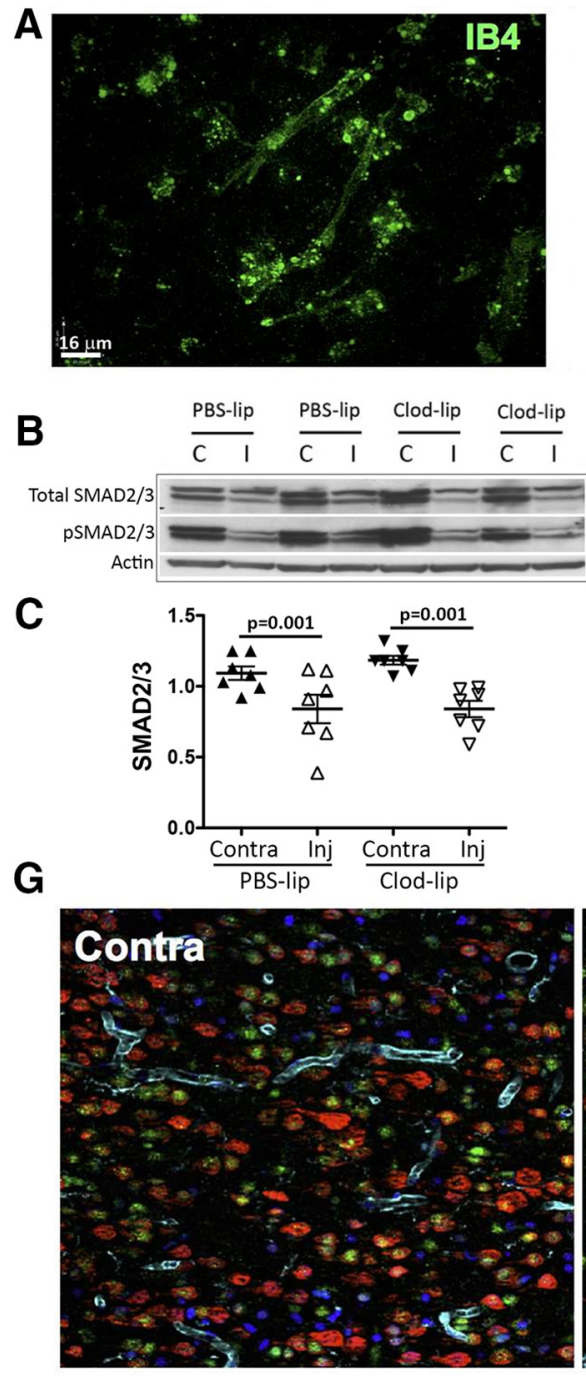
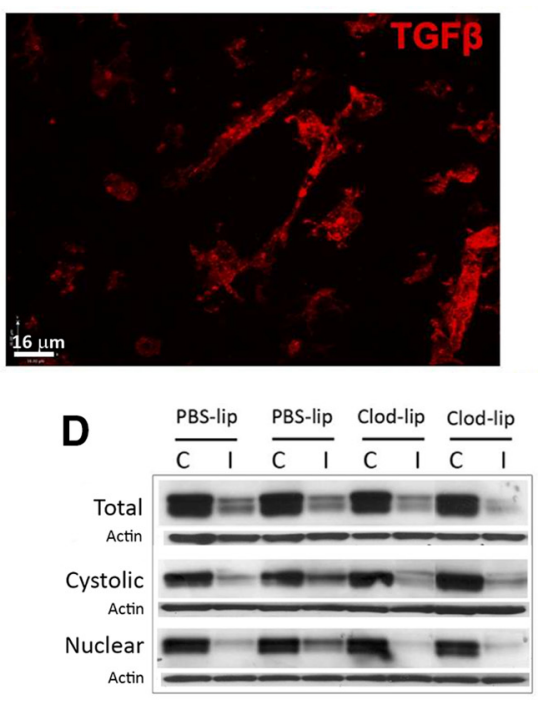

$\mathbf{E}$

Total Cyto Nuclear $\mathrm{H} 1$ MKK3 $=$
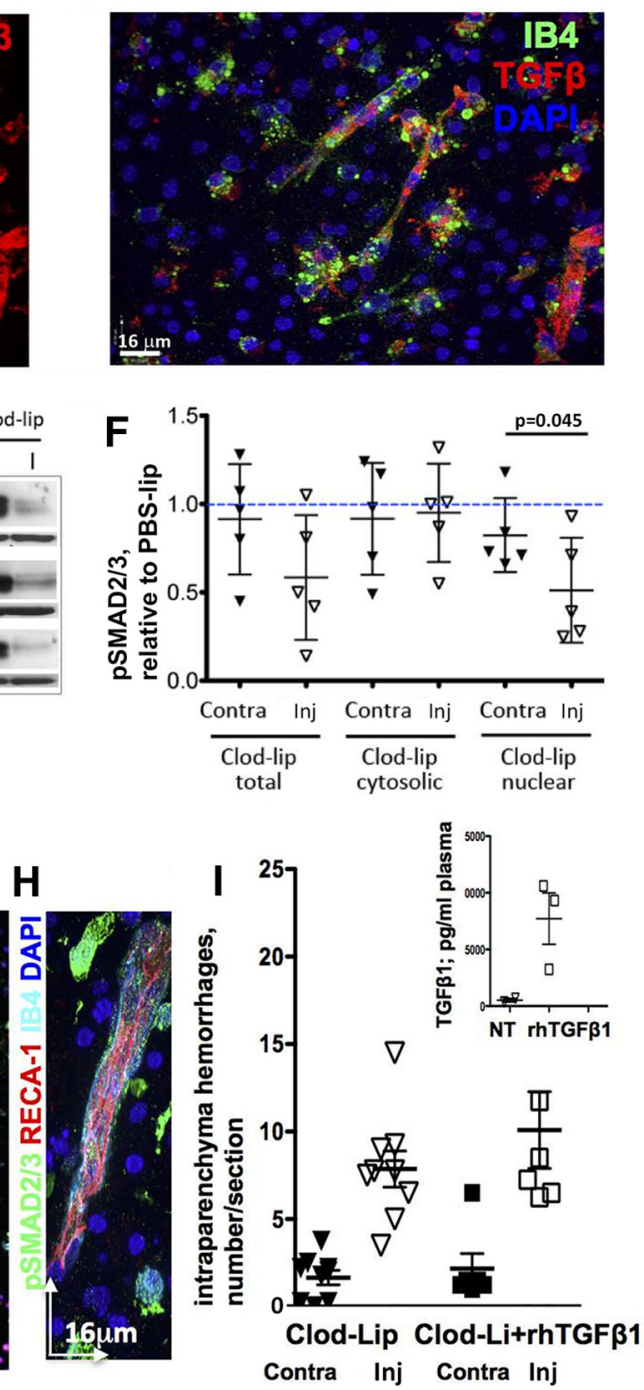

Figure 6. Replenishment of peripheral TGF $\beta 1$ does not attenuate hemorrhage occurrence at $24 \mathrm{~h}$ after $\mathrm{MCA} 0 \mathrm{in}$ rat pups with depleted microglia. $A$, Representative images showing expression of TGF $\beta 1$ in IB4 ${ }^{+}$brain vessels and microglia/macrophages in the injured cortex. $\boldsymbol{B}$, Western blots showing protein expression of SMAD2/3 (top) and pSMAD2/3 (middle) in the same total tissue lysates at $24 \mathrm{~h}$ after $\mathrm{TMCAO}$. The data are normalized to actin (bottom) in individual samples. C, tMCAO significantly and similarly reduces SMAD2/3 expression in injured regions of PBS-lip-treated and Clod-lip-treated rats. A common tissue sample was used in multiple Western blots to allow data analysis. $\boldsymbol{D}$, Western blots showing SMAD2/3 phosphorylation in total lysates and in cytosolic and nuclear fractions. E, Purity of the subcellular fractions is assessed by the presence of specific cytosolic (MKK3) and nuclear (histone H1) proteins. $F$, Densitometric quantification of pSMAD2/3 protein in total lysates and in the cytosolic and nuclear fractions. Shown are PSMAD2/3 values in individual Clod-lip rats expressed relative to averaged pSMAD2/3 value in PBS-lip rats in the same individual blots. G, Cell-type specific patterns of SMAD2/3 phosphorylation in contralateral (left) and ipsilateral (right) regions. Note SMAD2/3 phosphorylation in NeuN ${ }^{+}$neurons (red) in uninjured regions and in the penumbra but not in the ischemic core. pSMAD2/3 is expressed in IB4 ${ }^{+}$vessels in both uninjured and injured regions. $\boldsymbol{H}$, High-magnification image of pSMAD2/3 in a IB4 ${ }^{+}$vessel and in both IB4 ${ }^{+}$and IB4 ${ }^{-}$cells in the vicinity of a vessel. I, Quantification of the total number of intraparenchymal hemorrhages in rats treated with Clod-lip, with or without intravenous administration of rhTGF $\beta 1$. G, Inset, Plasma levels of TGF $\beta 1$ measured by Bioplex ELISA at $24 \mathrm{~h}$ after tMCAO in untreated rats and in rats injected rhTGF $\beta 1$ intravenously $18 \mathrm{~h}$ after tMCA0.

few small-size $\mathrm{DiI}^{+}$-lip were observed in $\mathrm{IB}^{-}{ }^{-}$or Iba1 ${ }^{-}$cells, as shown in Figure 7A, $C$ (thin arrows). No DiI ${ }^{+}$-lip were observed in morphologically intact pSMAD ${ }^{+}$neurons (Fig. $7 A$, on the left from injured region) and in neurons with morphologically integrant (Fig. $7 C$, asterisk) or apoptotic nuclei (Fig. $7 C$, thin white arrows). SMAD2/3 phosphorylation in neurons outside of injured region was unaffected (Fig. $7 A$, arrows), but SMAD2/3 phosphorylation was reduced or lost in activated microglia containing $\mathrm{DiI}^{+} / \mathrm{SB}-431542^{+}$liposomes (Fig. $7 B$, arrowheads). Treatment did not affect injury volume (data not shown), but led to significantly increased number of intraparenchymal hemorrhages in injured regions at $24 \mathrm{~h}$ (Fig. 7D). Meningeal hemorrhages were also observed. No increase in hemorrhage number was observed in contralateral hemisphere. Thus, TGFbr2/ALK5 inhibition in otherwise functional microglial cells induces hem- orrhages after neonatal stroke, further demonstrating a key role of microglial TGF $\beta$ signaling in protecting neonatal brain from hemorrhages.

We focused on the microglial TGF $\beta 1 /$ TGFbr2/ALK5 signaling, but, considering the complexity of TGF $\beta 1$ signaling and likely cell-type specific differences in its contribution to injury, it would be important to determine the effects of rhTGF $\beta 1$ and/or SB-431542 administration into the brain on hemorrhages and injury.

Depletion of microglial cells exacerbates injury and induces hemorrhages in neonatal mice subjected to tMCAO

To determine whether the phenomenon of microglial protection from hemorrhages after tMCAO that we observed in injured neonatal rats occurs across different species, and to examine whether 

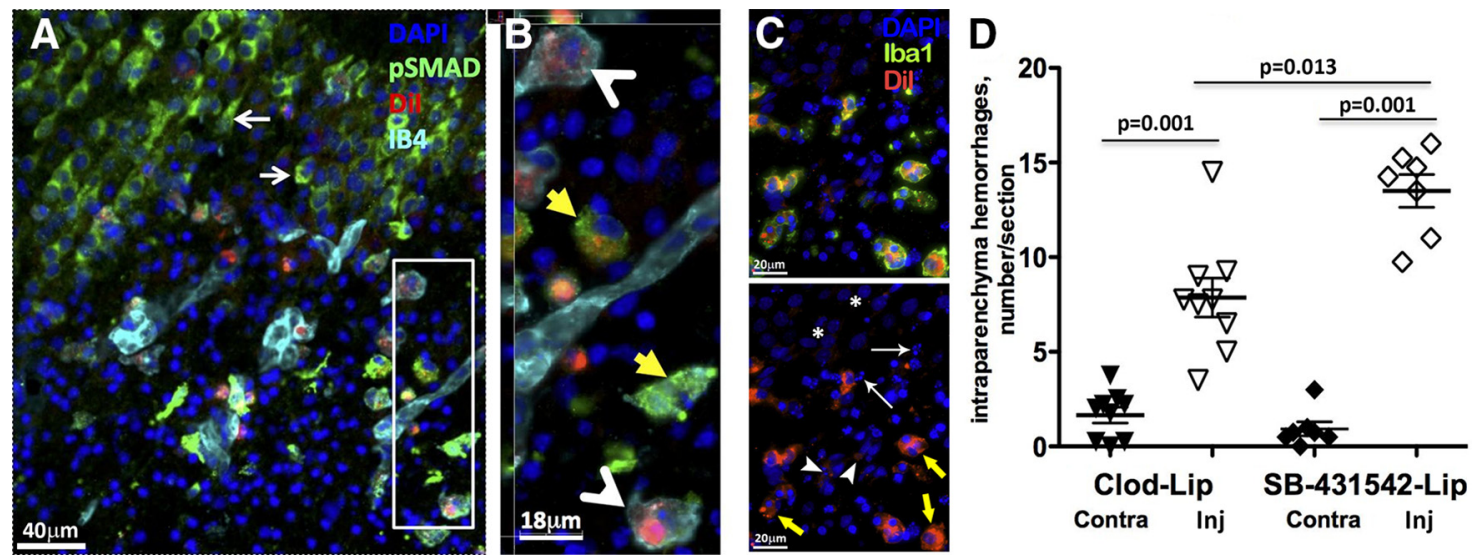

Figure 7. Selective inhibition of TGFbr2/ALK5 signaling in microglial cells induces hemorrhagic transformation $24 \mathrm{~h}$ after tMCAO.A, SMAD2/3 phosphorylation is reduced in IB4 ${ }^{+}$microglia that uptake $\mathrm{Dil}^{+} /$SB-431542-lip delivered intracortically. Essentially all Dil ${ }^{+}$cells are IB4 ${ }^{+}$microglia, and SMAD2/3 phosphorylation is observed in neurons outside of injury, as indicated by thin white arrows. $\boldsymbol{B}$, Magnified image from a region in $\boldsymbol{A}$ (white box). Yellow arrows point to cells with high pSMAD2/3 expression. White arrowheads point at IB4 ${ }^{+} / \mathrm{Dil}^{+}{ }^{+}$cells with low pSMAD2/3 signal. $\boldsymbol{C}$, Representative example of $\mathrm{Dil}^{+} / \mathrm{Iba1}^{+} / \mathrm{DAPI}^{+}{ }^{+}$immunofluorescence in the penumbra region of Dil ${ }^{+} / \mathrm{SB}$-431542-lip-treated rat. Essentially all $\mathrm{Dil}{ }^{+}$cells are double-labeled with Iba ${ }^{+}$(yellow arrows), whereas Dil ${ }^{+} / \mathrm{lba} 1^{-}$cells are infrequent, with low level of label incorporation (arrowheads). There is no Dil ${ }^{+}$signal around morphologically integrant nuclei outside of injured region $\left(^{*}\right.$, healthy neurons) or nuclei with apoptotic appearance (thin arrows). $\boldsymbol{D}$, The number of hemorrhages in injured hemisphere is significantly increased in rats treated with SB-431542-lip compared with Clod-lip-treated or nontreated rats.

monocytes account for the effects observed after microglial depletion, we examined the effects of intracortical Clod-lip injection before tMCAO in P9-P10 $\mathrm{Cx} 3 \mathrm{cr} 1^{\mathrm{GFP} /+} / \mathrm{Ccr} 2^{\mathrm{RFP} /+}$ mice, mice in which microglial cells are $\mathrm{Cx} 3 \mathrm{cr}^{\mathrm{GFP} /+}$ and monocytes are $\mathrm{Ccr} 2^{\mathrm{RFP} /+}$. Compared with PBS-lip injection, Clod-lip injection $48 \mathrm{~h}$ before tMCAO reduced the number of $\mathrm{Cx} 3 \mathrm{cr} 1 \mathrm{GFP} /+$ resting microglial cells in contralateral hemisphere to $76 \pm 21 \%$ in the caudate and $76 \pm 17 \%$ in the cortex. Compared with matching contralateral regions of Clod-lip-treated mice, the number of microglial cells was further significantly reduced in the ischemic core, in the core in the cortex (Fig. $8 D$ vs Fig. $8 B$; Fig. $8 F$ ) and in the caudate (data not shown).

Microglial depletion significantly exacerbated injury $24 \mathrm{~h}$ after reperfusion (Fig. 8G). Consistent with observations in rat pups, depletion significantly increased hemorrhage incidence (Fig. $8 H, I)$ and hemorrhages were observed in multiple brain regions, in the parenchyma, in the meninges, and in the choroid plexus. Microglial depletion also significantly induced albumin leakages into injured parenchyma of Clod-lip-treated mice, whereas the extent of leakage was negligible in PBS-treated mice at $24 \mathrm{~h}$ (data not shown). Unlike in neonatal rat pups, Clod-lip treatment produced smaller but significant increase in hemorrhage number in the contralateral hemisphere (Fig. $8 \mathrm{H}, I$ ).

Essentially, no Ccr2 $2^{\mathrm{RFP} /+}$ monocytes were observed in contralateral regions of untreated (data not shown), PBS-lip-treated, and Clod-lip-treated mice (Fig. $8 \mathrm{~J}$ ), whereas $\mathrm{Ccr} 2^{\mathrm{RFP} /+}$ monocytes were observed in injured regions, in the ischemic core, in the caudate (Fig. $8 \mathrm{~J}$ ) and in the penumbra (data not shown). The overall monocyte number varied in individual mice in each group, but there was not statistically significant difference between the groups. Quantification of the number of infiltrated monocytes (i.e., Ccr2 ${ }^{\mathrm{RFP} /+}$ cells not touching Glut ${ }^{+}$vessels) was similar in vehicle- and Clod-lip-treated mice (Fig. $8 \mathrm{~K}$ ). The number of peripheral monocytes was not significantly different between injured vehicle- and Clod-lip-treated mice (data not shown), demonstrating that hemorrhage induction was not due to monocyte depletion or altered monocyte infiltration. Cumulatively, these data in a second species, mice, revealed exacerbation of injury and induction of hemorrhages caused by microglial depletion, similar to effects in neonatal rats.

\section{Discussion}

We report a novel role of microglial cells in the context of neonatal brain ischemia, microglial-dependent protection from hemorrhages, and BBB disruption. We show that pharmacological depletion of microglia before neonatal stroke significantly increases injury and the incidence of intraparenchymal hemorrhages in rats and mice. In the rat stroke model, these effects are not directly mediated by loss or redistribution of intracellular TJ proteins or by perivascular Col-IV degradation caused by stroke. We demonstrate that activated microglial cells become a major source of TGF $\beta 1$ in injured neonatal brain, and loss of microgliaderived TGF $\beta 1 /$ ALK5 signaling after acute injury is not overcome by intravenous injection of $\operatorname{rhTGF} \beta 1$, indicating insufficiency of peripheral cytokine to rescue microglia-mediated protection. Pharmacological inhibition of TGF $\beta 1 /$ ALK5 signaling selectively in microglia during acute injury recapitulates the pattern of hemorrhage induction associated with microglial depletion. Depletion of microglia in $\mathrm{P} 9 \mathrm{Cx} 3 \mathrm{Cr}^{\mathrm{GFP} /+} / \mathrm{Ccr} 2^{\mathrm{RFP} /+}$ mice exacerbates injury after $\mathrm{tMCAO}$ and induces acute hemorrhages, but these effects are independent of infiltration of $\mathrm{Ccr} 2^{\mathrm{RFP} /+}$ monocytes into injured regions. Together with our previous findings that microglial depletion enhances neuronal injury and neuroinflammation, the newly identified direct role of microglia in protecting neurovascular integrity argues for the endogenous protective roles of these cells in injured neonatal brain.

Leakiness of the BBB has been firmly established in adult stroke models and many contributing mechanisms identified (Yang and Rosenberg, 2011). We recently reported that albumin leakage into injured brain regions is markedly lower in $\mathrm{P} 7$ rats after tMCAO than in adult rats after a similar insult and that neutrophil infiltration into ischemic-reperfused regions is low following neonatal tMCAO (Fernández-López et al., 2012), consistent with low infiltration in response to hypoxiaischemia in neonatal rats (Hudome et al., 1997), but in stark contrast with rapid neutrophil infiltration in adult tMCAO models (Mori et al., 1992). The markedly different patterns of tMCAO-induced gene upregulation and downregulation in endothelial cells between immature and adult brains 

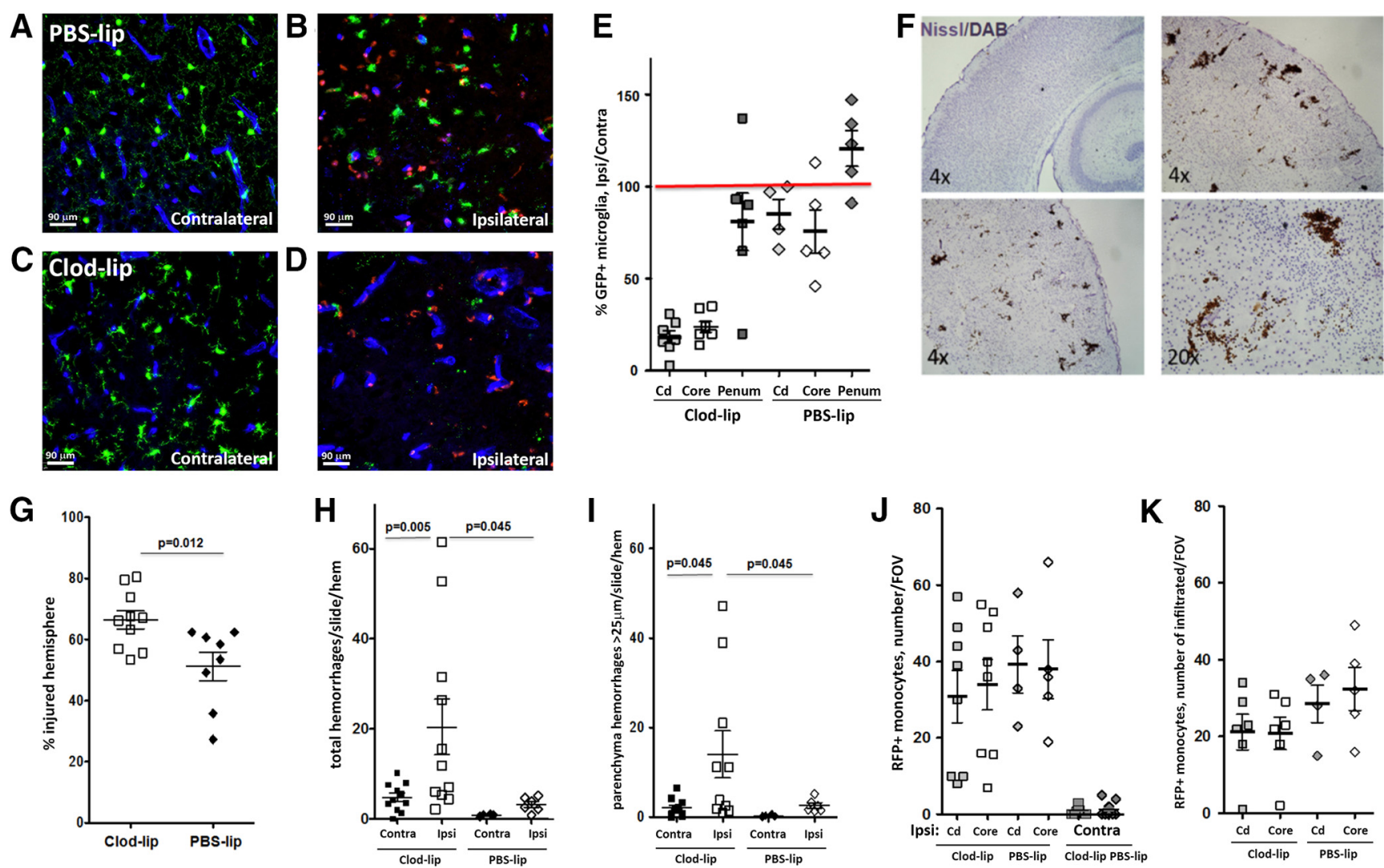

Figure 8. Microglial depletion exacerbates injury and promotes hemorrhages $24 \mathrm{~h}$ following neonatal arterial stroke in P9 mice. $\boldsymbol{A}-\boldsymbol{D}$, Representative images of $\left(\times 3 \mathrm{cr} 1{ }^{\text {GFP/ }+}\right.$ microglia and $\mathrm{CCR}^{\mathrm{RFP} /+}$ monocytes in ischemic core $(\boldsymbol{B}, \boldsymbol{D})$ and in matching contralateral cortical regions $(\boldsymbol{A}, \boldsymbol{C})$ of PBS-lip-treated $(\boldsymbol{A}, \boldsymbol{B})$ and $\mathrm{Clod}$-lip-treated $(\boldsymbol{C}, \boldsymbol{D})$ mice. Note morphological changes of $\mathrm{CX3} \mathrm{Cr}^{\mathrm{GFP} /+}$ in injured regions. Essentially no ${ }^{\mathrm{RFP} /+}$ monocytes are seen in contralateral hemisphere, whereas ${ }^{\mathrm{RFP} /+}$ monocytes are observed both in association with vessels and within injured cortex. E, Quantification of microglial depletion by Clod-lip in the caudate (Cd), the ischemic core, and in the penumbra (Penum). Shown data are percentage of CX3 $\mathrm{cr}{ }^{\mathrm{GFP} /+} \mathrm{microglial}_{\text {number in }}$ ipsilateral compared with matching contralateral regions in same individual animals. The number of $\mathrm{Cx} 3 \mathrm{cr}{ }^{\mathrm{GFP} /+}$ cells in contralateral hemisphere of Clod-lip-treated mice is lower than in contralateral hemisphere of PBS-lip-treated mice (data not shown). $\boldsymbol{F}$, Representative examples of hemorrhages identified on DAB/Nissl-stained coronal sections. $\mathbf{G}$, Microglial depletion significantly increases injury volume. Shown are data for individual mice. $\boldsymbol{H}, \boldsymbol{I}$, Microglial depletion significantly increases the total number of hemorrhages in multiple regions of injured hemisphere $(\boldsymbol{H})$ and the number of intraparenchyma hemorrhages $>25 \mu \mathrm{m}$ in the longest dimension $(\boldsymbol{I}) . \boldsymbol{J}, \boldsymbol{K}$, The total number of CCR2 ${ }^{\mathrm{RFP} /+}$ monocytes $(\boldsymbol{J})$ and the number of infiltrated $C\left(R 2^{\mathrm{RFP} /+}\right.$ monocytes $(\boldsymbol{K})$ in individual injured regions are not significantly different between Clod-lip and PBS-lip mice.

(Fernández-López et al., 2012), unsynchronized maturation of individual cell types, pericytes, and astrocytes, and of individual ECM components (Peppiatt et al., 2006; Zhang and Barres, 2010), and maturation-dependent vessel coverage by pericytes and astrocytes (Daneman et al., 2010) can contribute to differing postischemic BBB function in neonates compared with adults. Transport of other molecules through postnatal BBB can depend on injury model and species (Ek et al., 2015). The endfoot-basal lamina junctional complex is consolidated after the first postnatal week (Lunde et al., 2015), likely affecting protein interactions at the ECM-vascular-astrocyte interface. Microglia themselves undergo phenotypic changes during brain development (Butovsky et al., 2014).

Microglia are the main cell type that provides immunosurveillance in the brain and play essential roles in cell-cell communications, trophic support, and phagocytosis of dying cells (Ueno et al., 2013). Microglia have several direct effects on the vasculature, enabling embryonic vasculogenesis (Arnold and Betsholtz, 2013) and guiding vascular anastomosis (Fantin et al., 2010), effects not mediated by monocytes (Checchin et al., 2006). Microglia patrol the vasculature in naive adult brain (Davalos et al., 2012) and are rapid responders to the lesions (Nimmerjahn et al., 2005). Microglial cells play a unique role in postnatal brain by pruning synapses and shaping synaptic circuits (Paolicelli et al., 2011; Bialas and Stevens, 2013). After stroke activated microglia/macrophages have been thought toxic, along with peripheral leukocytes, by producing inflammatory mediators and adversely affecting BBB integrity (Iadecola and Anrather, 2011), but it remains questionable whether microglial cells, rather than perivascular microglia and invaded peripheral monocytes, mediate injury (Lambertsen et al., 2009).

In neonates, we investigated how microglial cells affect several injurious mechanisms demonstrated in adult stroke (Cunningham et al., 2005). We show that endothelial cell death triggered by tMCAO is exacerbated by the absence of microglia but that increased endothelial death is unlikely because of enhanced superoxide production in injured vessels, diminished VEGF expression, or enhanced neuroinflammation. Endothelial cells are vulnerable to ROS (Rizzo and Leaver, 2010), which are in part produced by reactive microglia after stroke in adults, but, to a lesser extent, in reactive microglia in neonates (Woo et al., 2012). In ischemic-reperfused neonatal brain regions, cytokine and chemokine increase is profound (Denker et al., 2007), but microglial depletion further increases the levels of inflammatory mediators, reduces removal of neuronal debris, and worsens parenchymal injury (Faustino et al., 2011). One of the main paths for albumin leakage in adult stroke is through disrupted TJ (Krueger et al., 2013), but microglial depletion does not lead to 
additional loss or further intracellular redistribution of occludin and claudin- 5 caused by tMCAO.

Col-IV degradation is a hallmark of hemorrhagic transformation after adult stroke (Asahi et al., 2001; Rosell et al., 2008). Mutations in the COL4A1 gene cause intracerebral hemorrhage both in newborn mice and humans (Gould et al., 2005). In humans, a limited number of genes, including MMP-9 and TGF $\beta$, predict strokes that later develop hemorrhagic transformation (Jickling et al., 2014). In adult stroke models, upregulated MMP-2, MMP-9, and MMP-3 mediate the breakdown of ECM components, contributing to disruption of the $\mathrm{BBB}$, brain edema, and injury, and predisposing to hemorrhagic transformation (Asahi et al., 2000). The origin of MMP-9-producing cells is imperative for early versus late hemorrhagic transformation, with MMP-9 primarily produced by neutrophils in acute stroke, but produced by brain cells at later points in the adult (Gidday et al., 2005; Jickling et al., 2014).

In human newborns, MMP-9 activation predicts HIE outcome (Bednarek et al., 2012). MMP-9 inhibition protects the neonatal rodent brain from hypoxia-ischemia (Chen et al., 2009). We show marked increase in activated MMP-9 in injured regions and microglia as an important source of MMP-9 that leads to robust degradation of a Col-IV $\alpha 1$ subunit. Yet, the magnitude of Col-IV $\alpha 1$ degradation is unaffected by the absence of microglia at $24 \mathrm{~h}$, making Col-IV degradation an unlikely cause for increased permeability or hemorrhages. Lack of phagocytotic microglia needed to clear hemorrhages (Zhao et al., 2009) likely contributes to continued presence of hemorrhages over $72 \mathrm{~h}$, but the presence of residual basal lamina in the absence of endothelial cells ("string vessels") also points to endothelial degeneration rather than loss of vascular sheaths as a primary mechanism of hemorrhages caused by microglia depletion. It is somewhat counterintuitive that the magnitude of Col-IV $\alpha 1$ degradation is unaffected by microglial depletion when active MMP-9 is diminished and that hemorrhagic transformation is increased when microglial MMP-9 is absent. Other proteases, such as fibronectin, perlecan, and agrin, could contribute to Col-IV degradation and affect interactions between ECM and endothelial cells and pericytes in the absence of microglia.

TGF $\beta 1$ contributes to neurovascular protection and serves as a survival factor for brain capillaries and BBB stability (Walshe et al., 2009). Multiple brain cell types express TGF $\beta 1$ in adult brain and upregulate TGF $\beta 1$ after stroke (Pál et al., 2014). Abrogated TGF $\beta 1$ signaling in astrocytes exacerbates subacute injury after distal MCAO and increases microglial activation and monocyte infiltration (Cekanaviciute et al., 2014). Deletion of peripheral monocytes or CCR2 in bone marrow-derived cells produces vessel irregularities, thinning and delayed hemorrhagic transformation in stroke, effects that are reversed by intracerebral TGF1 $\beta 1$ injection (Gliem et al., 2012). Similar to adults, in neonates, neurons and endothelial cells express TGF $\beta 1$ in uninjured regions, but TGF $\beta 1$ is lost in injured neurons, retained in endothelial cells, is not apparent in astrocytes, but is markedly upregulated in activated microglia in injured regions, mediating TGFbr2/SMAD2/3 signaling in the latter cells. Our attempt to revert depletion-induced hemorrhage by increasing peripheral TGF $\beta 1$ levels in proximity to injured vessels did not affect injury size or the number/size of hemorrhages, whereas inhibited TGF $\beta 1 /$ TGFbr2/ALK5 signaling selectively in microglia reduced SMAD2/3 phosphorylation in these cells and significantly increased the number of intraparenchymal hemorrhages.

Findings that monocytes in adult stroke (Gliem et al., 2012) and activated microglia in neonatal stroke in our study protect from postischemic hemorrhages and that TGF $\beta 1$ signaling is involved in protection in both situations make it tempting to as- sume that the underlying mechanisms are the same. However, in adult mice, hemorrhagic transformation following prolonged perfusion deficits (Jickling et al., 2014) or monocyte depletion (Gliem et al., 2012) is not apparent for days, whereas in our study hemorrhages occur early after reperfusion. There are many common features between resident microglia and monocytes, but microglia are of different origin than monocytes (Ginhoux et al., 2010) and make a self-renewable population, with a unique gene signature compared with monocytes and dendritic cells (Butovsky et al., 2014). Monocytes that infiltrate an injured adult brain do not contribute to the resident microglial pool (Ajami et al., 2011), whereas microglial phenotypes are heterogeneous, with stimulus-specific responses in vivo (Petersen and Dailey, 2004; Chhor et al., 2013).

To identify whether monocyte behavior is altered by microglial depletion and ultimately accounts for brain hemorrhages, we examined monocyte numbers in peripheral blood and in the brain in $\mathrm{P} 9 \mathrm{Cx} 3 \mathrm{cr} 1^{\mathrm{GFP} /+} / \mathrm{Ccr} 2^{\mathrm{RFP} /+}$ mice following tMCAO. We observed that infiltration of Ccr $2^{\mathrm{RFP} /+}$ monocytes into injured regions is rather limited and, importantly, is not affected by microglial depletion, suggesting that microglial TGF $\beta 1$-dependent signaling carries neurovascular protection.

In conclusion, we discovered an important role of microglial cells in protecting neonatal brain from ischemia-induced hemorrhages. Findings that this phenomenon is observed in two species suggest uniformness of effects and raise a question whether strategies aimed to broadly inhibit microglial function should be used after acute neonatal stroke. An improved understanding of the microglial phenotypes and role of individual phenotypes in governing neurovascular integrity in injured immature brain, together with acquired knowledge of whether BBB disruption and hemorrhagic transformation are governed by distinct mechanisms, would help in identifying new and more selective therapeutic strategies. Development of new tools to deplete the entire microglial population (Elmore et al., 2014) or individual subpopulation (Lalancette-Hébert et al., 2007) may allow a better understanding of the effects of parenchymal and perivascular microglia on injured vasculature. Identification of the role of microglial TGF $\beta 1$ as neurovascular protectant may lead to new therapeutic targets for neonatal stroke, especially when autocrine and paracrine mechanisms of microglial TGF $\beta 1$ in the injured brain are better defined and in relation to TGF $\beta 1$ signaling in other cell types.

\section{References}

Ajami B, Bennett JL, Krieger C, McNagny KM, Rossi FM (2011) Infiltrating monocytes trigger EAE progression, but do not contribute to the resident microglia pool. Nat Neurosci 14:1142-1149. CrossRef Medline

Armstrong-Wells J, Johnston SC, Wu YW, Sidney S, Fullerton HJ (2009) Prevalence and predictors of perinatal hemorrhagic stroke: results from the Kaiser Pediatric Stroke Study. Pediatrics 123:823-828. CrossRef Medline

Arnold T, Betsholtz C (2013) The importance of microglia in the development of the vasculature in the central nervous system. Vasc Cell 5:4. CrossRef Medline

Asahi M, Asahi K, Jung JC, del Zoppo GJ, Fini ME, Lo EH (2000) Role for matrix metalloproteinase 9 after focal cerebral ischemia: effects of gene knockout and enzyme inhibition with BB-94. J Cereb Blood Flow Metab 20:1681-1689. CrossRef Medline

Asahi M, Wang X, Mori T, Sumii T, Jung JC, Moskowitz MA, Fini ME, Lo EH (2001) Effects of matrix metalloproteinase-9 gene knock-out on the proteolysis of blood-brain barrier and white matter components after cerebral ischemia. J Neurosci 21:7724-7732. Medline

Bednarek N, Svedin P, Garnotel R, Favrais G, Loron G, Schwendiman L, Hagberg H, Morville P, Mallard C, Gressens P (2012) Increased MMP-9 and TIMP-1 in mouse neonatal brain and plasma and in human neonatal 
plasma after hypoxia-ischemia: a potential marker of neonatal encephalopathy. Pediatr Res 71:63-70. CrossRef Medline

Bialas AR, Stevens B (2013) TGF-beta signaling regulates neuronal C1q expression and developmental synaptic refinement. Nat Neurosci 16:17731782. CrossRef Medline

Bruno CJ, Beslow LA, Witmer CM, Vossough A, Jordan LC, Zelonis S, Licht DJ, Ichord RN, Smith SE (2014) Haemorrhagic stroke in term and late preterm neonates. Arch Dis Child Fetal Neonatal Ed 99:F48-F53. CrossRef Medline

Butovsky O, Jedrychowski MP, Moore CS, Cialic R, Lanser AJ, Gabriely G, Koeglsperger T, Dake B, Wu PM, Doykan CE, Fanek Z, Liu L, Chen Z, Rothstein JD, Ransohoff RM, Gygi SP, Antel JP, Weiner HL (2014) Identification of a unique TGF-beta-dependent molecular and functional signature in microglia. Nat Neurosci 17:131-143. CrossRef Medline

Cekanaviciute E, Fathali N, Doyle KP, Williams AM, Han J, Buckwalter MS (2014) Astrocytic transforming growth factor-beta signaling reduces subacute neuroinflammation after stroke in mice. Glia 62:1227-1240. CrossRef Medline

Checchin D, Sennlaub F, Levavasseur E, Leduc M, Chemtob S (2006) Potential role of microglia in retinal blood vessel formation. Invest Ophthalmol Vis Sci 47:3595-3602. CrossRef Medline

Chen W, Hartman R, Ayer R, Marcantonio S, Kamper J, Tang J, Zhang JH (2009) Matrix metalloproteinases inhibition provides neuroprotection against hypoxia-ischemia in the developing brain. J Neurochem 111: 726-736. CrossRef Medline

Chhor V, Le Charpentier T, Lebon S, Oré MV, Celador IL, Josserand J, Degos V, Jacotot E, Hagberg H, Sävman K, Mallard C, Gressens P, Fleiss B (2013) Characterization of phenotype markers and neuronotoxic potential of polarised primary microglia in vitro. Brain Behav Immun 32: 70-85. CrossRef Medline

Cunningham LA, Wetzel M, Rosenberg GA (2005) Multiple roles for MMPs and TIMPs in cerebral ischemia. Glia 50:329-339. CrossRef Medline

Daneman R, Zhou L, Kebede AA, Barres BA (2010) Pericytes are required for blood-brain barrier integrity during embryogenesis. Nature 468: 562-566. CrossRef Medline

Davalos D, Ryu JK, Merlini M, Baeten KM, Le Moan N, Petersen MA, Deerinck TJ, Smirnoff DS, Bedard C, Hakozaki H, Gonias Murray S, Ling JB, Lassmann H, Degen JL, Ellisman MH, Akassoglou K (2012) Fibrinogeninduced perivascular microglial clustering is required for the development of axonal damage in neuroinflammation. Nat Commun 3:1227. CrossRef Medline

Denes A, Thornton P, Rothwell NJ, Allan SM (2010) Inflammation and brain injury: acute cerebral ischaemia, peripheral and central inflammation. Brain Behav Immun 24:708-723. CrossRef Medline

Denker SP, Ji S, Lee SY, Dingman A, Derugin N, Wendland WF, Vexler ZS (2007) Macrophages are comprised of resident brain microglia, not infiltrating peripheral monocytes acutely after neonatal stroke. J Neurochem 100:893-904. CrossRef Medline

Derugin N, Dingman A, Wendland MF, Fox C, Bollen A, Vexler ZS (2005) Magnetic resonance imaging as a surrogate measure for histological chronic endpoint in a neonatal rat stroke model. Brain Res 1066:49-56. CrossRef Medline

Doyle KP, Cekanaviciute E, Mamer LE, Buckwalter MS (2010) TGFbeta signaling in the brain increases with aging and signals to astrocytes and innate immune cells in the weeks after stroke. J Neuroinflammation 7:62. CrossRef Medline

Ek CJ, D’Angelo B, Baburamani AA, Lehner C, Leverin AL, Smith PL, Nilsson H, Svedin P, Hagberg H, Mallard C (2015) Brain barrier properties and cerebral blood flow in neonatal mice exposed to cerebral hypoxiaischemia. J Cereb Blood Flow Metab 35:818-827. CrossRef Medline

Elmore MR, Najafi AR, Koike MA, Dagher NN, Spangenberg EE, Rice RA, Kitazawa M, Matusow B, Nguyen H, West BL, Green KN (2014) Colony-stimulating factor 1 receptor signaling is necessary for microglia viability, unmasking a microglia progenitor cell in the adult brain. Neuron 82:380-397. CrossRef Medline

Fantin A, Vieira JM, Gestri G, Denti L, Schwarz Q, Prykhozhij S, Peri F, Wilson SW, Ruhrberg C (2010) Tissue macrophages act as cellular chaperones for vascular anastomosis downstream of VEGF-mediated endothelial tip cell induction. Blood 116:829-840. CrossRef Medline

Faustino J, Wang X, Johnson CE, Klibanov A, Derugin N, Wendland MF, Vexler ZS (2011) Microglial cells contribute to endogenous brain de- fenses after acute neonatal focal stroke. J Neurosci 31:12992-13001. CrossRef Medline

Fernández-López D, Faustino J, Daneman R, Zhou L, Lee SY, Derugin N, Wendland MF, Vexler ZS (2012) Blood-brain barrier permeability is increased after acute adult stroke but not neonatal stroke. J Neurosci 32:9588-9600. CrossRef Medline

Fernández-López D, Natarajan N, Ashwal S, Vexler ZS (2014) Mechanisms of perinatal arterial ischemic stroke. J Cereb Blood Flow Metab 34: 921-932. CrossRef Medline

Gidday JM, Gasche YG, Copin JC, Shah AR, Perez RS, Shapiro SD, Chan PH, Park TS (2005) Leukocyte-derived matrix metalloproteinase-9 mediates blood-brain barrier breakdown and is proinflammatory after transient focal cerebral ischemia. Am J Physiol Heart Circ Physiol 289: H558-H568. CrossRef Medline

Ginhoux F, Greter M, Leboeuf M, Nandi S, See P, Gokhan S, Mehler MF, Conway SJ, Ng LG, Stanley ER, Samokhvalov IM, Merad M (2010) Fate mapping analysis reveals that adult microglia derive from primitive macrophages. Science 330:841-845. CrossRef Medline

Gliem M, Mausberg AK, Lee JI, Simiantonakis I, van Rooijen N, Hartung HP, Jander S (2012) Macrophages prevent hemorrhagic infarct transformation in murine stroke models. Ann Neurol 71:743-752. CrossRef Medline

Gould DB, Phalan FC, Breedveld GJ, van Mil SE, Smith RS, Schimenti JC, Aguglia U, van der Knaap MS, Heutink P, John SW (2005) Mutations in Col4al cause perinatal cerebral hemorrhage and porencephaly. Science 308:1167-1171. CrossRef Medline

Greenberg DA, Jin K (2013) Vascular endothelial growth factors (VEGFs) and stroke. Cell Mol Life Sci 70:1753-1761. CrossRef Medline

Hansen TM, Moss AJ, Brindle NP (2008) Vascular endothelial growth factor and angiopoietins in neurovascular regeneration and protection following stroke. Curr Neurovasc Res 5:236-245. CrossRef Medline

Hudome S, Palmer C, Roberts RL, Mauger D, Housman C, Towfighi J (1997) The role of neutrophils in the production of hypoxic-ischemic brain injury in the neonatal rat. Pediatr Res 41:607-616. CrossRef Medline

Iadecola C, Anrather J (2011) The immunology of stroke: from mechanisms to translation. Nat Med 17:796-808. CrossRef Medline

Jickling GC, Liu D, Stamova B, Ander BP, Zhan X, Lu A, Sharp FR (2014) Hemorrhagic transformation after ischemic stroke in animals and humans. J Cereb Blood Flow Metab 34:185-199. CrossRef Medline

Kirton A, Deveber G (2013) Life after perinatal stroke. Stroke 44:3265-3271. CrossRef Medline

Knowland D, Arac A, Sekiguchi KJ, Hsu M, Lutz SE, Perrino J, Steinberg GK, Barres BA, Nimmerjahn A, Agalliu D (2014) Stepwise recruitment of transcellular and paracellular pathways underlies blood-brain barrier breakdown in stroke. Neuron 82:603-617. CrossRef Medline

Krueger M, Härtig W, Reichenbach A, Bechmann I, Michalski D (2013) Blood-brain barrier breakdown after embolic stroke in rats occurs without ultrastructural evidence for disrupting tight junctions. PLoS One 8:e56419. CrossRef Medline

Lalancette-Hébert M, Gowing G, Simard A, Weng YC, Kriz J (2007) Selective ablation of proliferating microglial cells exacerbates ischemic injury in the brain. J Neurosci 27:2596-2605. CrossRef Medline

Lambertsen KL, Clausen BH, Babcock AA, Gregersen R, Fenger C, Nielsen $\mathrm{HH}$, Haugaard LS, Wirenfeldt M, Nielsen M, Dagnaes-Hansen F, Bluethmann H, Faergeman NJ, Meldgaard M, Deierborg T, Finsen B (2009) Microglia protect neurons against ischemia by synthesis of tumor necrosis factor. J Neurosci 29:1319-1330. CrossRef Medline

Liu J, Jin X, Liu KJ, Liu W (2012) Matrix metalloproteinase-2-mediated occludin degradation and caveolin-1-mediated claudin-5 redistribution contribute to blood-brain barrier damage in early ischemic stroke stage. J Neurosci 32:3044-3057. CrossRef Medline

Lunde LK, Camassa LM, Hoddevik EH, Khan FH, Ottersen OP, Boldt HB, Amiry-Moghaddam M (2015) Postnatal development of the molecular complex underlying astrocyte polarization. Brain Struct Funct 220: 2087-2101. CrossRef Medline

Lynch JK, Nelson KB (2001) Epidemiology of perinatal stroke. Curr Opin Pediatr 13:499-505. CrossRef Medline

Monje ML, Toda H, Palmer TD (2003) Inflammatory blockade restores adult hippocampal neurogenesis. Science 302:1760-1765. CrossRef Medline

Mori E, del Zoppo GJ, Chambers JD, Copeland BR, Arfors KE (1992) Inhibition of polymorphonuclear leukocyte adherence suppresses no-reflow 
after focal cerebral ischemia in baboons. Stroke 23:712-718. CrossRef Medline

Munger JS, Sheppard D (2011) Cross talk among TGF-beta signaling pathways, integrins, and the extracellular matrix. Cold Spring Harb Perspect Biol 3:a005017. CrossRef Medline

Nimmerjahn A, Kirchhoff F, Helmchen F (2005) Resting microglial cells are highly dynamic surveillants of brain parenchyma in vivo. Science 308: 1314-1318. CrossRef Medline

Pál G, Lovas G, Dobolyi A (2014) Induction of transforming growth factor beta receptors following focal ischemia in the rat brain. PLoS One 9:e106544. CrossRef Medline

Pál G, Vincze C, Renner É, Wappler EA, Nagy Z, Lovas G, Dobolyi A (2012) Time course, distribution and cell types of induction of transforming growth factor betas following middle cerebral artery occlusion in the rat brain. PLoS One 7:e46731. CrossRef Medline

Paolicelli RC, Bolasco G, Pagani F, Maggi L, Scianni M, Panzanelli P, Giustetto M, Ferreira TA, Guiducci E, Dumas L, Ragozzino D, Gross CT (2011) Synaptic pruning by microglia is necessary for normal brain development. Science 333:1456-1458. CrossRef Medline

Peppiatt CM, Howarth C, Mobbs P, Attwell D (2006) Bidirectional control of CNS capillary diameter by pericytes. Nature 443:700-704. CrossRef Medline

Petersen MA, Dailey ME (2004) Diverse microglial motility behaviors during clearance of dead cells in hippocampal slices. Glia 46:195-206. CrossRef Medline

Polfliet MM, Goede PH, van Kesteren-Hendrikx EM, van Rooijen N, Dijkstra CD, van den Berg TK (2001) A method for the selective depletion of perivascular and meningeal macrophages in the central nervous system. J Neuroimmunol 116:188-195. CrossRef Medline

Rizzo MT, Leaver HA (2010) Brain endothelial cell death: modes, signaling pathways, and relevance to neural development, homeostasis, and disease. Mol Neurobiol 42:52-63. CrossRef Medline

Rosell A, Cuadrado E, Ortega-Aznar A, Hernández-Guillamon M, Lo EH,
Montaner J (2008) MMP-9-positive neutrophil infiltration is associated to blood-brain barrier breakdown and basal lamina type IV collagen degradation during hemorrhagic transformation after human ischemic stroke. Stroke 39:1121-1126. CrossRef Medline

Saederup N, Cardona AE, Croft K, Mizutani M, Cotleur AC, Tsou CL, Ransohoff RM, Charo IF (2010) Selective chemokine receptor usage by central nervous system myeloid cells in CCR2-red fluorescent protein knock-in mice. PLoS One 5:e13693. CrossRef Medline

Ueno M, Fujita Y, Tanaka T, Nakamura Y, Kikuta J, Ishii M, Yamashita T (2013) Layer V cortical neurons require microglial support for survival during postnatal development. Nat Neurosci 16:543-551. CrossRef Medline

van Rooijen N, Hendrikx E (2010) Liposomes for specific depletion of macrophages from organs and tissues. Methods Mol Biol 605:189-203. CrossRef Medline

Walshe TE, Saint-Geniez M, Maharaj AS, Sekiyama E, Maldonado AE, D'Amore PA (2009) TGF-beta is required for vascular barrier function, endothelial survival and homeostasis of the adult microvasculature. PLoS One 4:e5149. CrossRef Medline

Wang Q, Tang XN, Yenari MA (2007) The inflammatory response in stroke. J Neuroimmunol 184:53-68. CrossRef Medline

Woo MS, Wang X, Faustino JV, Derugin N, Wendland MF, Zhou P, Iadecola C, Vexler ZS (2012) Genetic deletion of CD36 enhances injury after acute neonatal stroke. Ann Neurol 72:961-970. CrossRef Medline

Yang Y, Rosenberg GA (2011) Blood-brain barrier breakdown in acute and chronic cerebrovascular disease. Stroke 42:3323-3328. CrossRef Medline

Zhang Y, Barres BA (2010) Astrocyte heterogeneity: an underappreciated topic in neurobiology. Curr Opin Neurobiol 20:588-594. CrossRef Medline

Zhao X, Grotta J, Gonzales N, Aronowski J (2009) Hematoma resolution as a therapeutic target: the role of microglia/macrophages. Stroke 40:S92S94. CrossRef Medline 